Relmecs, diciembre 2018, vol. 8, no. 1, e037, ISSN 1853-7863

Universidad Nacional de La Plata. Facultad de Humanidades y Ciencias de la Educación. Centro Interdisciplinario de Metodología de las Ciencias Sociales.

Red Latinoamericana de Metodología de las Ciencias Sociales

\title{
El déficit habitacional en Argentina. Una propuesta de medición para establecer magnitudes, tipos y áreas prioritarias de intervención intra-urbana
}

\author{
Housing deficit in Argentina. A proposal for measuring magnitudes, \\ types and priority of intra-urban intervention
}

\author{
Mariana Marcos *, María Mercedes Di Virgilio** y Gabriela Mera* \\ * Instituto de Investigaciones Gino Germani, CONICET, Universidad de Buenos Aires - Uiversidad Nacional de \\ Tres de Febrero, Argentina, **Instituto de Investigaciones Gino Germani, CONICET, Universidad de Buenos Aires, \\ Argentina | marianamarcos.ar@gmail.com, mercedes.divirgilio@gmail.com. gabsmera@yahoo.com
}

\section{PALABRAS CLAVE}

Déficit habitacional

Metodología

Análisis micro-espacial

KEYWORDS

Housing deficit

Methodology

Microspatial analysis

\section{RESUMEN}

El objetivo del trabajo es realizar una propuesta de medición del déficit habitacional en Argentina que abarque las múltiples dimensiones de la problemática, identifique tipos de intervención y niveles de criticidad en la intervención y proporcione información para unidades geoestadísticas pequeñas. Se desarrolla el proceso de operacionalización de este concepto, desde su definición operacional hasta el cálculo de los indicadores que componen sus dimensiones, tomando como punto de partida una propuesta del Ministerio de Vivienda y Urbanismo de Chile. Finalmente se realiza una aplicación en un municipio de la Región Metropolitana de Buenos Aires que permita observar las potencialidades analíticas de la propuesta.

\section{ABSTRACT}

This paper aims to provide a methodological proposal for measuring the housing deficit in Argentina, that cover the multiple dimensions of the problem, identify types of intervention and urgency levels, and provide information for small geostatistical units. The process of operationalization of this concept is developed, from its operational definition to the calculation of the statistical indicators that make up its dimensions, taking as its starting point a proposal by the Ministry of Housing and Urban Development of Chile. Finally, an application is made in a municipal district of the Metropolitan Area of Buenos Aires, which allows to observe the analytical potential of the proposal. 


\section{Introducción $\underline{1}$}

La situación habitacional en Argentina constituye una cuestión tan vigente entre las preocupaciones de los hogares como en el campo académico, político y social. En una población caracterizada por el crecimiento demográfico moderado pero de signo siempre positivo $\underline{2}$, la prolongación de la vida en estado de buena salud -y con ello la prolongación de las posibilidades de seguir ocupando la vivienda particular, con la consecuente postergación de la herencia por parte de hijos y nietos-, la caída cada vez más en desuso (y la valoración negativa) de los arreglos residenciales que incluyen el allegamiento de varios hogares en una vivienda y la conformación de hogares extensos o compuestos, las necesidades habitacionales continúan multiplicándose. Y ello sobre la base de un parque habitacional y políticas sectoriales permanentemente en deuda con los sectores más postergados de la población, que residen en viviendas deficitarias en cuanto a su calidad constructiva, la disponibilidad de servicios y su tamaño.

A esta difícil pregunta por el déficit habitacional -su magnitud, sus características tipológicas y sus niveles de intensidad-, en la actualidad se suma la demanda de información precisa acerca de su localización, y del impacto micro-territorial de las intervenciones. Asimismo, hay que considerar que las políticas públicas sectoriales que se han desarrollado durante el siglo XXI para paliar el déficit de viviendas han tenido a los gobiernos locales como protagonistas. Las iniciativas públicas se han gestionado bajo modalidades descentralizadas y/o desconcentradas, dejando en el nivel local las decisiones acerca de las poblaciones y los territorios a atender. En este marco, los municipios se afianzan progresivamente como receptores directos de las demandas de la población, conocedores de la multidimensionalidad de las problemáticas, gestores y ejecutores de programas habitacionales nacionales y provinciales, y hasta diseñadores de políticas integrales de base territorial. La producción de información estadística viene acompañando este proceso en curso, pudiéndose mencionar entre otros hitos la creación de un Sistema de Estadísticas Locales en el Instituto Nacional de Estadística y Censos, los esfuerzos por dotar de más y mejor información a la Secretaría de Asuntos Municipales del Ministerio del Interior y la inclusión por primera vez en una base de datos censal de la variable municipio en el año 2010. En cuanto al nivel intra-municipal, han sido fundamentales para la producción de información a esa escala la progresiva puesta a disposición de los usuarios de las bases de microdatos censales y su correspondiente cartografía, y las innovaciones informáticas que permiten su manipulación integral a través de procesadores estadísticos y sistemas de información geográfica.

En este marco, la posibilidad de brindar una respuesta efectiva a la cuestión habitacional involucra evaluar el parque habitacional existente, tanto en términos de calidad y cantidad, como en términos de su adecuación a la estructura de los hogares y las familias, y a sus posibilidades económicas, sin desatender las aspiraciones de no compartir la vivienda con otros hogares o con otras personas ajenas al núcleo familiar y considerando la dimensión micro-territorial del fenómeno.

El presente trabajo se plantea como objetivo, precisamente, realizar una propuesta de medición del déficit habitacional en Argentina que cumpla a la vez con los requisitos de: a) abarcar las múltiples dimensiones de la problemática, permitiendo identificar y cuantificar los distintos requerimientos de intervención que se derivan de ellas; b) distinguir diferentes niveles de criticidad, permitiendo identificar aquellas situaciones en las que las condiciones de vida de los hogares se ven más seriamente comprometidas; y, c) proporcionar información para unidades espaciales de tamaño pequeño, de modo de poder obtener resultados micro-espaciales para evaluar el impacto de políticas habitacionales territorialmente localizadas y realizar diagnósticos de situación global para las unidades de gestión del territorio (municipios, provincias y total del país).

El punto de partida es la propuesta de medición del Ministerio de Vivienda y Urbanismo (MINVU) de Chile, que tiene la ventaja de basarse en una noción del déficit habitacional integral y de lograr su cuantificación a partir del procesamiento de la información censal. En este sentido, el trabajo chileno allana el camino hacia una medición del déficit habitacional con las características planteadas aquí, en tanto que parte de una definición operacional del concepto equivalente a la que se utiliza en este trabajo y recurre a la única fuente de datos que cumple con los requisitos de cubrir la totalidad del territorio del país y de publicarse para unidades geoestadísticas de tamaño reducido. 
No obstante, el antecedente del MINVU requiere ser adaptado a las posibilidades que brinda el censo argentino, a las convenciones locales en materia de construcción de indicadores sociodemográficos y a la necesidad de identificación de las situaciones habitacionales más apremiantes. A ello se agrega una dificultad adicional: el censo argentino más reciente no recabó la totalidad de los datos de forma universal, lo cual limita la cantidad de información susceptible de ser procesada para niveles de desagregación territorial exigentes. El presente trabajo espera constituir un aporte metodológico en este sentido, dando cuenta de forma meticulosa y detallada de las decisiones, criterios y procedimientos involucrados en el proceso de sortear los importantes desafíos mencionados, de modo de garantizar la replicabilidad y eventual adaptación del instrumento desarrollado por parte de otros investigadores y profesionales.

\subsection{El déficit habitacional en la región: definiciones y antecedentes de medición}

La medición y especificación del déficit habitacional constituye un insumo fundamental para la política sectorial de vivienda. En un contexto en el que, tanto a nivel internacional como nacional, los marcos normativos reconocen el derecho a la vivienda, su medición se convierte en una cuestión socialmente problematizada. $\underline{3}$

Sin embargo, y a pesar de la importancia que reviste, la medición del déficit habitacional no escapa a los avatares que median en la construcción de índices o medidas que permiten dar cuenta de fenómenos o problemáticas sociales. La construcción de un índice está necesariamente atada a la definición que investigadores y/o técnicos hacen del fenómeno en cuestión y, por ende, a sus concepciones acerca del mismo. Cuanto más complejo es el fenómeno que interesa medir, más compleja es la cadena definicional que involucra su medición. De este modo, la dificultad en la medición del déficit habitacional se relaciona con la complejidad del problema que se intenta medir y, también, con el proceso de medición en sí; es decir, con las dificultades asociadas a la definición del fenómeno, al diseño de indicadores pertinentes y a la disponibilidad de fuentes que permiten dar cuenta de ellos.

En relación con la definición de este fenómeno y las operacionalizaciones derivadas, en la región han dominado dos formas de medir los requerimientos habitacionales. Por una parte, aquella que da cuenta del déficit cuantitativo, que estima la cantidad de viviendas que la sociedad debe construir o adicionar al parque existente para que haya una relación uno a uno entre viviendas adecuadas y hogares. Dimensionar el déficit cuantitativo supone diferenciar el parque de viviendas inadecuado del adecuado y conocer la demanda potencial de viviendas por medio de variables referidas al agrupamiento de las personas en hogares y núcleos familiares. Por otra, la que alude al déficit cualitativo, que se refiere a las viviendas particulares que deben ser mejoradas o ampliadas para formar parte del stock de viviendas adecuadas y que, en la actualidad, presentan problemas de orden material, sanitario o inadecuación de tamaño susceptibles de ser subsanados (se trata de viviendas inadecuadas pero recuperables) (Arriagada, 2005; MINUVI, 2007).

Para la medición de ambas dimensiones del déficit se han desarrollado diferentes propuestas. $\stackrel{4}{\text { Las mismas se }}$ distinguen por la diversidad de aspectos que consideran en la conceptualización y cuantificación de los requerimientos habitacionales. En relación a la medición del déficit cuantitativo, las propuestas más restrictivas se basan en la comparación entre el número de hogares y el de viviendas permanentes, sin considerar los materiales utilizados en su construcción o su estado de conservación.

Si bien a simple vista pareciera ser que estas variables son de carácter más bien cualitativo, tienen un trasfondo que trasciende este aspecto. Una vivienda cuyo techo es de un material tan precario que no impide la entrada de lluvias y temporales, no cumple con el objetivo de proteger a sus moradores contra las inclemencias del tiempo, por lo que esta situación debiera considerarse como parte del déficit cuantitativo (Szalachman, 2000, p. 11).

Aquellas propuestas que van más allá de la adecuación entre cantidad de hogares y viviendas, en cambio, tienen en cuenta el tipo de materiales predominantes en la construcción del techo, las paredes y los pisos de las viviendas -dependiendo de la disponibilidad de los datos existentes_- ${ }^{5}$. La consideración de los aspectos constructivos de la vivienda permite, de este modo, definir una situación estándar con base en la cual valorar las condiciones mínimas 
de habitabilidad para una vivienda adecuada (Fresneda, 1997). $\underline{6}$

El déficit cualitativo, por su parte, se evalúa a través de dos dimensiones referidas a necesidades de mejoramiento de la vivienda: la disponibilidad de servicios y la calidad y el estado de la construcción de la vivienda (véase nota 1). En algunas mediciones, el hacinamiento puede aparecer como una tercera dimensión del déficit cualitativo, en tanto da cuenta de una situación de inadecuación entre el tamaño del hogar y el tamaño de la vivienda que debe ser resuelta a través de la ampliación de esta última. Otros trabajos logran hilar lo suficientemente fino como para verificar la presencia de núcleos allegados económicamente independientes en los hogares hacinados. Ello constituye un matiz sumamente relevante, dado que en esos casos es deseable que el problema habitacional sea resuelto mediante la construcción de una nueva vivienda para ese núcleo familiar con capacidad económica para llevar adelante una vida doméstica independiente. En estos estudios, el hacinamiento puede derivar entonces en mayores niveles de déficit cuantitativo y/ o cualitativo.

Tanto las medidas de déficit cuantitativo como cualitativo pueden variar de acuerdo con las particularidades que asuma la problemática en contextos específicos - por ejemplo, la adecuación al medio urbano y/o rural y, por ende, la definición de estándares específicos- (un ejemplo de ello puede leerse en Galvín, 2011). En este sentido, interesa destacar que el alcance de ambos conceptos está muy ligado a las características de los contextos en los que se aplican y a los estándares socialmente definidos como necesarios o indispensables para habitar (Galvis, 2011). De este modo, el carácter situado y contextual de las medidas -que involucran la aplicación de criterios diversos para definir el déficit habitacional- impone limitaciones para comparar los tipos de carencia habitacional entre países y/o regiones (Sepúlveda y Fernández Wagner, 2006).

Finalmente, es necesario atender al hecho de que el déficit habitacional cuantitativo y el déficit habitacional cualitativo son fenómenos que pueden presentarse por separado o afectar a los mismos hogares. En este sentido, no corresponde adicionarlos o sumarlos. Las medidas que dan cuenta de ellos tampoco abarcan exhaustivamente al fenómeno del déficit habitacional por separado, pues cada una individualmente no logra captar la complejidad de la problemática.

El déficit cualitativo no capta la necesidad de privacidad y autonomía que representa para una familia u hogar el contar con una vivienda propia y, [por su parte] el déficit cuantitativo, no considera las viviendas adicionales que sería necesario reparar o construir, dada la precariedad de las actuales (Galvis, 2011, p. 10).

\subsection{Déficit habitacional y políticas públicas}

Los diferentes tipos de déficit habitacional requieren ser abordados, desde el ámbito de la intervención pública, mediante soluciones de distinta índole. El déficit cuantitativo "motiva como respuesta institucional la construcción de nuevas unidades de vivienda que permiten satisfacer las necesidades de las familias allegadas o sin techo y reemplazar el conjunto de viviendas que no resultan habitables debido a su extremada precariedad material”. Por su parte, el déficit cualitativo "vehiculiza otra clase de acciones públicas, que se vinculan con la reparación, el mejoramiento y/o ampliación de las viviendas ya ocupadas que presentan situaciones deficitarias en uno o más atributos relacionados con la materialidad, servicios, saneamiento o tamaño de los recintos” (MINVU, 2007, p, 4). ${ }^{7}$ Identificar (y articular) ambas dimensiones del déficit no constituye una cuestión menor, pues toda la política de vivienda debería generar iniciativas que atiendan tanto a la producción de vivienda como a la consolidación, mantención y reparación del parque habitacional existente (Arriagada, 2003). $\underline{8}$

Estas formas de conceptualizar el déficit se focalizan en las características del parque habitacional y en su capacidad para dar respuesta a las necesidades de vivienda de los hogares, pero no se detienen en las características de dichos hogares, salvo en lo que atañe a su tamaño. A pesar de ello, constituyen un insumo básico para avanzar en la descripción e identificación de los hogares que se encuentran dentro de las múltiples situaciones que estas definiciones recortan, así como para construir medidas que permitan dar cuenta del problema en diferentes escalas territoriales -barrial, local, metropolitana, etc.-. Asimismo, se presentan como aspectos 
centrales a la hora de pensar intervenciones públicas en materia habitacional. Si la política habitacional pretende ser sustentable en el tiempo, no sólo deberá contemplar las necesidades habitacionales que presentan los hogares sino, también, las condiciones en las que desarrollan su vida cotidiana -relación entre miembros activos e inactivos, cantidad de perceptores de ingresos, edad de los miembros, condiciones de participación en el mercado de trabajo de los miembros activos, etc.- y las posibilidades efectivas que tienen de hacer frente a los requerimientos económicos que impondrá la nueva situación habitacional, así como la localización de dichos hogares y el peso de su presencia en el territorio.

En la región es posible identificar algunos trabajos que proponen medidas de déficit habitacional que permitan abordar integralmente el problema y los requerimientos de información que plantea la política pública. Entre ellos se destaca la propuesta del Ministerio de Vivienda y Urbanismo de Chile (MINVU, 2007). El objetivo de esta iniciativa ha sido cuantificar la magnitud y características del déficit habitacional desde una perspectiva integral, que contemple la heterogeneidad de requerimientos que se configura a partir de múltiples determinantes sociodemográficos y habitacionales. En este sentido, plantean un abordaje teórico-metodológico que considera ambas dimensiones del déficit (cuantitativo y cualitativo), a las que suman la medición de las condiciones económicas de los hogares para enfrentar los cambios en su situación habitacional. De este modo, la propuesta considera las condiciones físicas de habitabilidad de las viviendas -en función de su materialidad, tipo y disponibilidad de servicios básicos que hacen al saneamiento- e incorpora, también, el rol que juega la composición de los hogares que la habitan -la existencia de más de un hogar compartiendo vivienda, la presencia de múltiples núcleos familiares y la adecuación entre el tamaño de la vivienda y de los hogares que residen en ella- y las posibilidades económicas que presentan los hogares como para afrontar arreglos residenciales de otro tipo y solventar los gastos que implica el acceso a una vivienda nueva.

En relación con los indicadores utilizados interesa señalar que, en concordancia con las definiciones más restringidas mencionadas anteriormente, los mismos se centran en el estado de la construcción de los inmuebles, clasificando a los hogares según desarrollen su vida cotidiana en viviendas inadecuadas irrecuperables, viviendas deficitarias recuperables o viviendas buenas. Estas tres categorías son elaboradas a partir de medidas vinculadas con el tipo de vivienda que los hogares habitan, sus características constructivas y la dotación de servicios a la que acceden. $\mathrm{Y}$ a ellas se suma una cuarta medida que relaciona las características de la vivienda con la composición de los hogares, incorporando entre las situaciones deficitarias a aquellas familias que conviven en condiciones de hacinamiento (dos o más personas por cuarto) y/o allegamiento (Herzer y Di Virgilio, 2011).

Respecto a las fuentes de datos para el estudio del déficit habitacional, en diversos trabajos y propuestas se evidencia que los censos de población constituyen la fuente con mayor potencial para el estudio del déficit, su desagregación y localización espacial. Por un lado, en la medida en que permite captar información sobre las múltiples unidades que están vinculadas con la identificación de necesidades habitacionales: viviendas, hogares y núcleos familiares (CELADE, 1996). Por el otro, en tanto la disponibilidad de microdatos procesables a escalas microespaciales permite generar estadísticas de déficit desagregadas para el diseño de múltiples tipos de intervenciones públicas a nivel local y/o metropolitano (Arriagada, 2003). Sin embargo, como recuerda Arriagada (2003, 2011) en la región -excepto casos puntuales en Brasil (Fundación Joao Pinheiro), Chile (MINVU, 2007; Arriagada y Moreno, 2007) y más recientemente Paraguay- persiste una subutilización de las bases de datos del censo de vivienda "incluso respecto a tareas intermedias como generar tipologías de materialidad y saneamiento, o bien para procesar datos de hogares” (Arriagada, 2011, p. 26). En este sentido, la presente propuesta de medición espera constituir un aporte para los estudios argentinos, que ponga en evidencia las potencialidades de la información censal para la construcción de medidas complejas que permitan aproximarse a esta problemática desde una perspectiva integral. $\underline{9}$

\section{Metodología}

En el marco del desarrollo de un instrumento de medición del déficit habitacional, replicable en diferentes 
contextos del país y en escalas territoriales diversas, el censo de población emerge como la fuente de datos por antonomasia, dado que a) empadrona a todas las viviendas, los hogares y la población, y recoge información sobre cada una de esas unidades de análisis, y b) es exhaustivo, lo que permite estudios a cualquier nivel de agregación territorial de la información; aunque no hay que olvidar que también tiene debilidades, derivadas del acotado número de preguntas sobre cada temática (CELADE, 1996, p. 17).

Por otro lado, cualquier intento de medición integral del déficit habitacional, debe partir de la definición de aquellas unidades domésticas que requieren vivienda (los hogares, y, dentro de ellos, los núcleos familiares que pudieran conformarlo) y de las condiciones que deben cumplir las viviendas para atender satisfactoriamente las necesidades habitacionales: i) protección frente a las inclemencias del medio; ii) disponibilidad de un espacio de intimidad y privacidad; y iii) ofrecimiento de un ambiente inmediato sano (Rodríguez, 1999, p. 211).

En un seminario previo a la ronda de los censos del 2000, la CEPAL incluye al déficit habitacional entre los temas a investigar, y recomienda captar a través de las cédulas censales las siguientes variables para computar el déficit de vivienda (Rodríguez, 1999, p. 112):

- Número de hogares

- Tipo de vivienda

- Condición de ocupación

- Estado de la vivienda

- Cantidad de personas

- Cantidad de cuartos o dormitorios

- Superficie

- Tipo (calidad) de los materiales (muro, piso y techo)

- Disponibilidad de servicios básicos (agua, eliminación de excretas, electricidad)

Relación de parentesco

Los censos argentinos modernos tradicionalmente han relevado la mayor parte de la información recomendada, con la excepción de la superficie de la vivienda y de las relaciones de parentesco entre miembros del hogar distintos del jefe. La ausencia de información correspondiente a la superficie de la vivienda se compensa, en buena medida, con datos acerca del tamaño de los hogares y cantidad de cuartos o dormitorios disponibles, que permiten calcular las clásicas medidas de hacinamiento. En cambio, la información correspondiente a las relaciones de parentesco entre miembros del hogar distintos del jefe es difícilmente sustituible y representa quizás uno de los mayores desafíos de trabajar la problemática del déficit habitacional a partir de datos censales, puesto que se ve condicionada la identificación fehaciente de núcleos familiares secundarios dentro de los hogares.

No obstante estas salvedades, los censos argentinos cumplen con los criterios recomendados por los organismos internacionales para la captación empírica de los componentes del déficit habitacional, y constituyen una oportunidad invaluable para producir información para diferentes niveles territoriales de análisis.

La aplicación de la propuesta de medición del déficit habitacional conllevó una serie de desafíos metodológicos fundamentales, entre ellos, el gran reto de adaptar una propuesta pensada para otro contexto a las posibilidades que brindan las fuentes de datos argentinas, en este caso, el Censo Nacional de Población, Hogares y Viviendas, la única fuente que, en virtud de su universalidad, permite producir datos para la totalidad del país y desagregar la información a niveles micro-espaciales, de manera de poder captar las especificidades y microdiferencias que caracterizan las actuales dinámicas espaciales (Mera y Marcos, 2012).

Este desafío de adaptación -que implica analizar, compatibilizar y tomar decisiones metodológicas respecto a las variables involucradas en la construcción de los diversos indicadores y los umbrales considerados críticos para dar cuenta de las múltiples dimensiones del déficit habitacional- conllevó dificultades adicionales en el caso del último censo, relevado en el 2010. En este último, en continuidad con la metodología implementada en los censos de 1980 y 1991, se aplicaron técnicas de muestreo para relevar los datos en las áreas más pobladas del país, con el fin de simplificar el operativo censal, reducir costos y acelerar la obtención de resultados. En estas áreas se 
utilizaron dos tipos de cuestionarios: un cuestionario básico (que contiene una cantidad reducida de preguntas, referidas a las características de la vivienda y los hogares, el parentesco entre los miembros del hogar, y la edad, sexo, lugar de nacimiento, condición de actividad y situación educacional de las personas) y un cuestionario ampliado (que incluye las preguntas del básico, y además otras que amplían la información sobre la condición migratoria y la situación ocupacional de las personas, al tiempo que indagan en la fecundidad y la seguridad social, entre otras dimensiones y variables). Debido al diseño muestral implementado en el relevamiento censal, los datos provenientes del cuestionario ampliado no se encuentran disponibles para unidades geoestadísticas pequeñas.

Al llevar a cabo la adaptación de la propuesta de medición del déficit habitacional, se consideró de vital importancia la posibilidad de generar información a una escala micro-espacial, que permita dar cuenta de heterogeneidades que se producen a nivel intramunicipal, localizar problemáticas habitacionales específicas y evaluar el impacto de políticas públicas, así como también posibilitar la reconstrucción de otros territorios de interés al interior de los municipios (subdivisiones administrativas internas, tipos de hábitat particulares, etc.) sobre los cuales producir información. Por este motivo, se decidió trabajar exclusivamente con la base de datos del cuestionario censal básico que, si bien implicó trabajar a partir de una cantidad de variables mucho más reducida, a futuro posibilita obtener datos con altos niveles de desagregación espacial.

La Figura 1 sinteriza los determinantes operativos del déficit habitacional -la calidad material de la vivienda, la condición de allegamiento (externo e interno), la dependencia económica y el hacinamiento- y cómo se articulan sus respectivas categorías para identificar requerimientos vinculados con sus diversas modalidades: el déficit cuantitativo, el déficit cualitativo y la conjunción de ambos tipos de déficit.

\section{Figura 1. Tipo y magnitud del déficit habitacional según sus determinantes operativos}

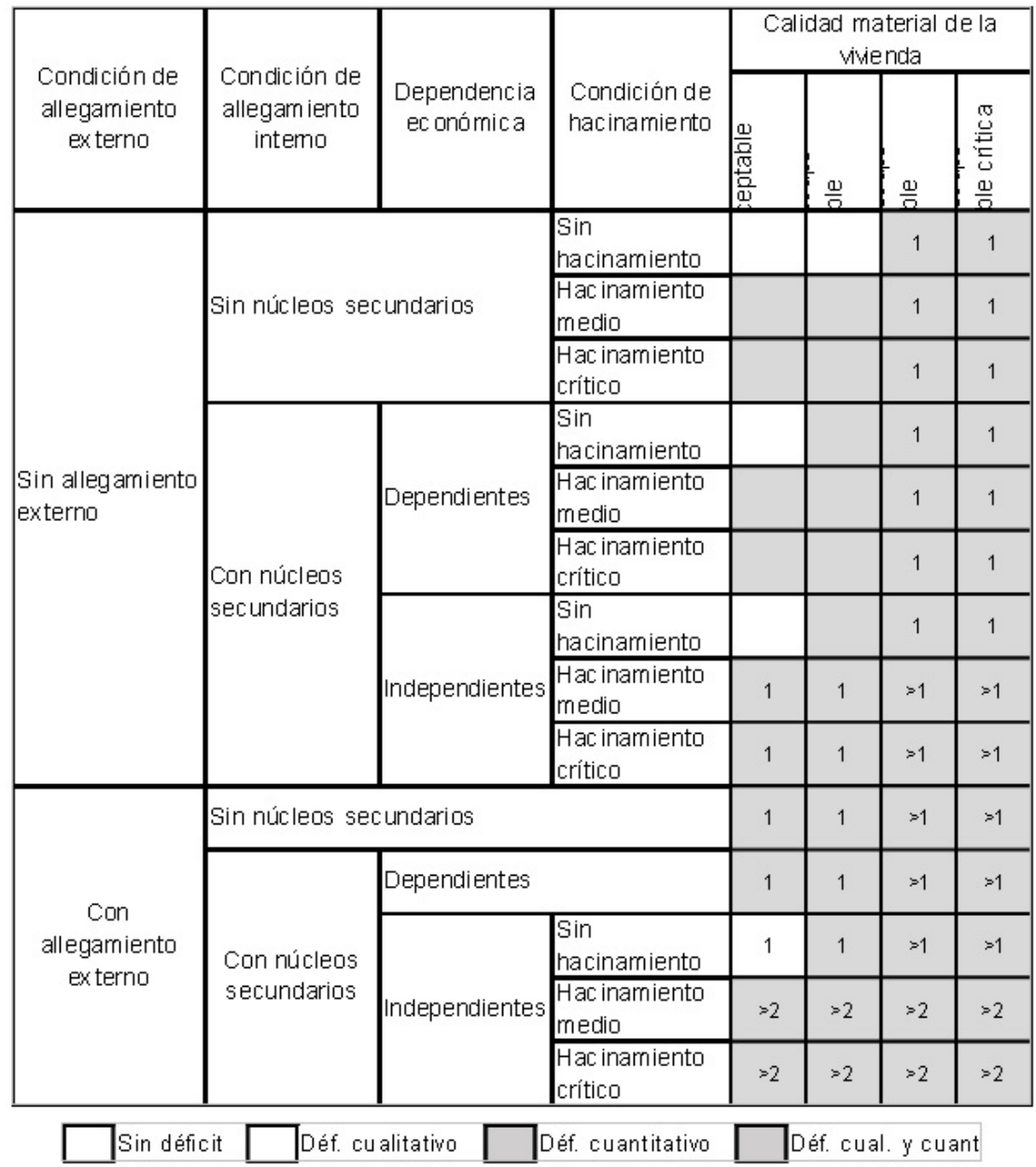


Nota: la cantidad exacta de viviendas a construir depende de la cantidad de hogares allegados y de núcleos allegados independientes que se encuentre en las viviendas.

Fuente: elaboración propia. Realización M. Marcos

Puede verse allí que el déficit cuantitativo se vincula con la existencia de: a) viviendas de calidad material irrecuperable o crítica (que requieren ser reemplazadas por nuevas unidades); o b) más de un hogar en la vivienda; o c) múltiples núcleos familiares económicamente independientes (que tienen la posibilidad de aspirar a una solución habitacional autónoma) en hogares hacinados. Por su parte, el déficit cualitativo se vincula con la presencia de: a) viviendas de calidad material recuperable (que requieren de acciones de mejoramiento); o b) viviendas de calidad material aceptable, pero con algún nivel de hacinamiento (que requieren de ampliación) y sin allegamiento de otros hogares o de núcleos secundarios económicamente independientes. $\frac{10}{\text { En las celdas }}$ sombreadas de la Figura 1, que corresponden al déficit cuantitativo, se indica la cantidad de unidades de vivienda que se requiere construir en cada caso. Hay situaciones donde la solución habitacional se logrará mediante la construcción de una única vivienda, y otras donde las necesidades de reemplazo de viviendas irrecuperables y de construcción de viviendas adicionales para hogares o núcleos secundarios allegados se presentan de manera simultánea y requieren de la construcción de más de una vivienda nueva.

A continuación, se detallan las diversas dimensiones que componen al déficit, dando cuenta de las definiciones, criterios y variables censales utilizadas para su cálculo.

\subsection{Condición de allegamiento externo}

La condición de allegamiento externo se vincula con la existencia de dos o más hogares cohabitando en una misma vivienda.

De acuerdo con los criterios censales, la vivienda -también denominada unidad de habitación- remite al recinto de alojamiento estructuralmente separado e independiente que ha sido construido para ser habitado por personas, o que se utiliza con ese fin en el momento del relevamiento del censo; incluyendo casas, departamentos, ranchos, casillas, piezas en inquilinatos u hoteles-pensión, locales no construidos para habitación, viviendas móviles y espacios en la vía pública utilizados como lugar de habitación o pernocte por personas en situación de calle. Por su parte, el hogar refiere a la persona o conjunto de personas que viven bajo el mismo techo y comparten los gastos de alimentación (INDEC, 2001).

En este sentido, la identificación de hogares allegados dentro de una misma vivienda incide en la magnitud del déficit habitacional cuantitativo, en la medida que se trata de personas o grupos de personas con un presupuesto alimentario propio, por lo que pueden aspirar a una solución habitacional independiente.

Para el cálculo de este indicador se procedió a:

1. establecer la cantidad de hogares por vivienda. Para ello se realizó un conteo de hogares en la vivienda, para el universo de las viviendas particulares ocupadas, excluyendo de este modo a las viviendas colectivas (mediante un filtro a partir de la variable Tipo de vivienda agrupado) y a las viviendas desocupadas (mediante un filtro a partir de la variable Condición de ocupación).

2. contabilizar el número de hogares allegados por vivienda, asignándole a las viviendas en las que se identificó más de un hogar en el conteo previo, un valor correspondiente al número de hogares por vivienda menos 1 .

3. establecer la cantidad total de hogares allegados, multiplicando el número de hogares allegados por la frecuencia correspondiente y sumando los productos. 


\subsection{Condición de allegamiento interno}

El allegamiento interno hace alusión a la existencia de núcleos familiares secundarios en un hogar, es decir, a la presencia de una pareja sola, una pareja con hijos, o un padre o madre con hijos, que forman parte de un hogar más amplio sin encabezarlo (sin que ninguno de los miembros del núcleo familiar sea el jefe del hogar más amplio).

En los cálculos del déficit habitacional, la identificación de situaciones de allegamiento interno por presencia de núcleos familiares secundarios se considera indispensable para establecer la magnitud del déficit cuantitativo, puesto que en el imaginario de la sociedad argentina contemporánea es deseable que cada núcleo familiar constituya un hogar independiente, sin tener que compartir los gastos de alimentación y la vivienda con otras personas.

Los censos argentinos no permiten identificar de forma fehaciente los núcleos familiares secundarios, puesto que sólo relevan las relaciones de parentesco entre el jefe y los restantes miembros del hogar, sin indagar en los vínculos de todas las personas entre sí. ${ }^{11}$ Sin embargo, se puede presumir la existencia de estos núcleos familiares allegados por la presencia en el hogar de ciertas categorías de la variable Relación de parentesco con el jefe (Figura 2):

- Núcleos secundarios de hijos unidos (con o sin hijos): núcleos familiares secundarios compuestos por un hijo/a del jefe y su pareja, y el añadido eventual de hijos. En términos operativos, se los identifica en el censo por la presencia de yernos/ nueras, y se contabilizan tantos núcleos secundarios de este tipo como yernos/ nueras haya en el hogar.

- Núcleos secundarios de hijas madres solteras: núcleos familiares secundarios compuestos por una hija no unida del jefe y su(s) propio(s) hijo(s). En este caso, al hecho de que los censos argentinos no permiten conocer quiénes son los padres de los nietos del jefe que se encuentran en el hogar, se adiciona la dificultad de que el Censo 2010 no incluyó las preguntas sobre la situación conyugal y el estado civil de las personas en el cuestionario básico aplicado a la totalidad de la población. De ello se desprende que se puede identificar a las hijas del jefe que conviven con él, pero no se puede conocer su situación conyugal. En este contexto, la aproximación a este tipo de núcleos secundarios se logró asumiendo que en todos los hogares en los que hay una hija de 14 o más años, al menos un nieto y ausencia de yernos/nueras, existe un núcleo secundario de madre soltera con hijos oculto.

- Núcleos secundarios de padres o suegros: núcleos familiares secundarios compuestos por los padres o suegros del jefe del hogar. Se contabiliza un núcleo secundario de este tipo cuando se encuentra dos personas del hogar clasificadas como padre/madre/suegro/a del jefe.

El total de núcleos allegados de cada hogar se obtiene por sumatoria de las tipologías de núcleo familiar secundario especificadas. 
Figura 2. Núcleos allegados identificados

$\begin{gathered}\text { núcleos secundarios } \\ \text { de hijos unidos }\end{gathered}$
$\begin{gathered}\text { núcleos secundarios } \\ \text { de hijas madres solteras }\end{gathered}$
$\begin{aligned} & \mathrm{Referencias} \\ & \mathrm{J}=\text { jefe } \\ & \mathrm{H}=\text { hijo/a } \\ & \mathrm{Y} / \mathrm{N}=\text { yerno/ nuera }\end{aligned}$
$\begin{aligned} & \mathrm{H}=\text { hija mujer }>\text { de } 13 \text { años } \\ & \mathrm{Pi} / \mathrm{M}=\text { nieto/a }\end{aligned}$

Fuente: elaboración propia. Realización: M. Marcos.

Debe recordarse que la cuantificación de los núcleos allegados puede haberse visto afectada porque el censo argentino es de hecho, empadrona a las personas en el lugar en que pasaron la noche de referencia del relevamiento, y la base de datos que se deriva de la información relevada mediante el cuestionario básico no contiene la variable Dónde vive habitualmente, que permitiría excluir a las personas eventualmente censadas en el hogar, pero que habitualmente residen en otro municipio de la provincia, otra provincia u otro país.

\subsection{Dependencia económica}

La dependencia económica del hogar refiere a la relación entre la cantidad de personas económicamente independientes (que perciben ingresos) y la cantidad de personas económicamente dependientes (que no perciben ingresos, por lo que constituyen cargas familiares para las personas económicamente independientes) a nivel de los hogares.

La posibilidad de dar cuenta de la (in)dependencia económica de los hogares constituye un elemento fundamental para identificar a los potencialmente demandantes de nuevas viviendas, en la medida que sólo los hogares que cuenten con una relativa autonomía económica pueden aspirar a solventar una solución habitacional independiente. En este sentido, la dependencia/independencia económica del hogar determinará el tipo de intervención para solucionar las necesidades habitacionales de un hogar allegado: una nueva vivienda (si el hogar cuenta con relativa independencia económica) o ampliación de la vivienda existente (si el hogar presenta una dependencia económica elevada).

Para el cálculo de este indicador se procedió a:

1. identificar la condición de dependencia económica de las personas, considerando para ello la disponibilidad corriente de ingresos, ya sea que estos provengan del trabajo remunerado o del cobro de jubilaciones. Esta condición se aborda de manera indirecta debido a que los censos de población argentinos no relevan información sobre ingresos. 
Se consideran personas independientes a: a) las personas en edad de trabajar (14 años o más) ocupadas al momento del censo (por lo que consecuentemente percibirían una retribución monetaria por su trabajo); y b) las personas que, por su edad, puede inferirse que están jubiladas (varones mayores de 69 y mujeres mayores de 65 años). Se infiere la cantidad de jubilados a partir de la edad de las personas porque la pregunta por la percepción de jubilación o pensión sólo se incluyó en el formulario censal ampliado. Esta inferencia constituye una aproximación válida en la medida que, en la actualidad, la tasa de cobertura del sistema previsional argentino es superior al 90\% (ANSES, 2010). Ese dato de la ANSES se cotejó con la información censal de 2010 que relevó el cuestionario ampliado, pudiéndose determinar que la cobertura extensiva (aunque no universal) se da en el grupo quinquenal de edad posterior al correspondiente a la edad jubilatoria de cada sexo (la edad jubilatoria es 60 años para los varones y 65 años para las mujeres, y la extensión de la cobertura se observa a partir del grupo de edad 65-69 en el caso de las mujeres y 70-74 en el caso de los varones).

Por su parte, se consideran personas dependientes a: a) las personas que no se encuentran en edad de trabajar (menores de 14 años); y b) las personas en edades potencialmente activas (entre 14 y 70 años en el caso de los varones, y entre 14 y 65 años en el caso de las mujeres) que se encuentran desocupadas o inactivas.

2. con estos criterios se procede a contabilizar el número de personas independientes y el número de personas dependientes en el hogar, para lo que se realiza un conteo de dichas personas (tal como fueron identificadas en el procesamiento anterior) por vivienda, para el universo de las viviendas particulares ocupadas.

3. una vez contabilizadas el número de personas independientes y el número de personas dependientes en el hogar, se procede a calcular el índice de dependencia económica como el cociente entre ambas variables. El procesamiento siempre se realiza para el universo de las viviendas particulares ocupadas, excluyendo a los hogares que no registren personas independientes (estos casos se imputan a la categoría de dependencia económica alta).

El resultado de este procesamiento (que da lugar a una variable continua) se categoriza de modo de identificar situaciones de:

- dependencia baja (hasta 1 persona dependiente por aportante del hogar),

- dependencia media (entre 1,01 y 2,5 personas dependientes por aportante) y

- dependencia alta (más de 2,5 personas dependientes por aportante).

\subsection{Condición de hacinamiento}

La condición de hacinamiento hace referencia a la adecuación entre el tamaño de los hogares y el de la vivienda, y se calcula a partir del cociente entre la cantidad total de personas del hogar y la cantidad total de habitaciones o piezas de las que dispone el mismo (sin considerar la cocina y el baño). El resultado se categoriza de modo de identificar situaciones de

- ausencia de hacinamiento (hasta 2 personas por cuarto),

- hacinamiento medio (entre 2,01 y 3 personas por cuarto), y

- de hacinamiento crítico (más de 3 personas por cuarto).

Conocer la condición de hacinamiento de los hogares es de vital importancia para identificar situaciones de déficit habitacional cualitativo cuya resolución requiere de la ampliación de la vivienda existente. Es el caso de viviendas en el que hay un único hogar o un hogar que incluye núcleos secundarios sin posibilidades económicas de 
independizarse, donde el hacinamiento puede determinar necesidades de ampliación del recinto de habitación en el que residen.

\subsection{Calidad de la vivienda}

La calidad de la vivienda hace referencia a las condiciones de habitabilidad que presenta una vivienda en función de su materialidad (considerando los atributos del piso y techo), la disponibilidad de servicios básicos que hacen al saneamiento (calidad del servicio de agua y calidad del servicio sanitario) y su tipo (distinguiéndose entre viviendas de tipo aceptable y viviendas de tipo irrecuperable, móviles u otras). A partir de estas tres dimensiones, se clasifica al parque habitacional de acuerdo a cuatro categorías: a) viviendas aceptables o buenas; b) viviendas recuperables; c) viviendas irrecuperables; y d) viviendas irrecuperables críticas.

La posibilidad de dar cuenta de la calidad de las viviendas constituye un factor esencial para calcular la magnitud y el tipo de déficit habitacional, permitiendo identificar la presencia de unidades de vivienda que no resultan habitables debido a su extremada precariedad, por lo que se vuelve necesario reemplazarlas (déficit cuantitativo) o bien la existencia de aspectos materiales deficitarios que requiere de intervenciones vinculadas con la reparación o el mejoramiento de determinados atributos (déficit cualitativo).

El cálculo de la calidad de las viviendas se fundamenta en una tipología -la Tipología de Calidad Global de la Vivienda-, cuya construcción resulta de la síntesis de tres tipologías parciales: a) la calidad material de la vivienda; b) la condición de saneamiento de la vivienda y c) el tipo de vivienda.

Interesa señalar aquí algunas cuestiones referidas a la construcción de dos de las tipologías parciales (la calidad material y la condición de saneamiento de la vivienda). Los censos argentinos toman al hogar como unidad de observación para relevar esos aspectos de la vivienda. Es decir que cada hogar declara cuáles son los materiales constructivos que predominan en su vivienda y de qué servicios dispone. Esto bajo el supuesto de que cuando en las viviendas hay más de un hogar, uno de ellos, frecuentemente el primero en ser empadronado por el censo, suele ocupar los ambientes mejor acondicionados, amplios y aprovisionados de servicios, mientras que el/los hogar/es restantes suelen tener condiciones habitacionales de menor calidad. En esta propuesta de estimación del déficit habitacional se atribuye a la vivienda la calidad material y el aprovisionamiento de servicios declarado por el primer hogar empadronado. Esta decisión teórico-metodológica no impacta en la calidad de la medida ni supone la subestimación de las viviendas deficitarias, puesto que para los hogares de rango superior a 1 la solución habitacional prevista es la construcción de vivienda nueva.

\subsubsection{Calidad material de la vivienda (CMV)}

Este indicador da cuenta de la calidad de los materiales constructivos de la vivienda, a partir del cruce de tres variables censales: a) material predominante de los pisos; b) material predominante de la cubierta exterior del techo; y c) revestimiento interior o cielorraso del techo.

A partir de ello, la CMV produce una clasificación que discrimina entre tres estados del parque habitacional (Figura 3):

- Aceptables: viviendas con calidad de techo aceptable (por contar con materiales de buena calidad en la cubierta exterior del techo y disponer de revestimiento interior o cielorraso) y con calidad de piso aceptable (por contar con materiales de buena calidad en los pisos, como cerámica, baldosa, mosaico, mármol, madera o alfombrado).

- Recuperables: viviendas con calidad de techo recuperable (por contar con materiales de buena calidad en la cubierta exterior del techo, pero sin revestimiento interior o cielorraso; o bien con materiales más deficitarios como chapa, palma, tabla o paja) y/o calidad de piso recuperable (por contar con materiales de menor calidad en los pisos, como cemento o ladrillo fijo). 
- Irrecuperables: viviendas con al menos un indicador irrecuperable, ya sea en relación con la calidad de techo (por estar construido de algún otro material irrecuperable) o con la calidad de los pisos (de tierra o ladrillo suelto, u otro material irrecuperable).

Figura 3. Calidad material de la vivienda

\begin{tabular}{|c|c|c|c|}
\hline \multirow[b]{2}{*}{ Calidad piso } & \multicolumn{3}{|c|}{ Calidad techo } \\
\hline & $\begin{array}{c}\text { aceptable } \\
\text { (cubierta asfáltica o } \\
\text { membrana/ } \\
\text { baldosa o losa/ } \\
\text { pizarra o teja/ } \\
\text { chapa de metal; con } \\
\text { cielorraso) }\end{array}$ & $\begin{array}{c}\text { recuperable } \\
\text { (cubierta asfáltica o } \\
\text { membrana/ baldosa o } \\
\text { losa/ pizarra o teja/ chapa } \\
\text { de metal; sin cielorraso - } \\
\text { chapa de fibrocemento o } \\
\text { plástico/ chapa de cartón/ } \\
\text { caña, palma, tabla o paja } \\
\text { con o sin barro) }\end{array}$ & $\begin{array}{l}\text { irrecuperable } \\
\text { (otro) }\end{array}$ \\
\hline $\begin{array}{l}\text { aceptable } \\
\text { (cerámica, baldosa, mosaico, } \\
\text { mármol, madera o alfombrado) }\end{array}$ & $\begin{array}{c}\text { CMV } \\
\text { aceptable }\end{array}$ & $\begin{array}{l}\text { CMV } \\
\text { recuperable }\end{array}$ & $\begin{array}{l}\text { CMV } \\
\text { irrecuperable }\end{array}$ \\
\hline $\begin{array}{l}\text { recuperable } \\
\text { (cemento o ladrillo fijo) }\end{array}$ & $\begin{array}{l}\text { CMV } \\
\text { recuperable }\end{array}$ & $\begin{array}{l}\text { CMV } \\
\text { recuperable }\end{array}$ & $\begin{array}{l}\text { CMV } \\
\text { irrecuperable }\end{array}$ \\
\hline $\begin{array}{l}\text { irrec uperable } \\
\text { (tierra o ladrillo suelto; otro) }\end{array}$ & $\begin{array}{l}\text { CMV } \\
\text { irrecuperable }\end{array}$ & $\begin{array}{l}\text { CMV } \\
\text { irrecuperable }\end{array}$ & $\begin{array}{l}\text { CMV } \\
\text { irrecuperable }\end{array}$ \\
\hline
\end{tabular}

Fuente: elaboración propia. Realización: M. Marcos.

\subsubsection{Condición de saneamiento de la vivienda (CSV)}

La condición de saneamiento es una medida de la calidad del parque habitacional basada en el cruce de dos dimensiones: la calidad del servicio sanitario de la vivienda (elaborada a partir de las variables censales: Tiene baño o letrina; Tiene botón, cadena o mochila para limpieza del inodoro; y Desagüe del inodoro) y la calidad del servicio de agua de la vivienda (considerando las variables censales: Tenencia de agua, y Procedencia del agua para beber y cocinar).

A partir de la combinación de ambas dimensiones, la CSV produce una clasificación que discrimina entre tres estados del parque habitacional (Figura 4):

- Aceptables: viviendas con calidad del servicio sanitario aceptable (por contar con baño con botón, cadena o mochila para el inodoro y descarga a red pública o cámara séptica y pozo ciego) y calidad del servicio de agua aceptable, tanto en términos de su provisión como de su procedencia (el contar con agua de red pública por cañería dentro de la vivienda).

- Deficitarias: viviendas con calidad del servicio sanitario deficitario (por no tener baño, o bien porque el inodoro no cuenta con botón/cadena/mochila, o bien por contar con inodoro con botón/cadena/mochila, 
pero con descarga sólo a pozo ciego, a hoyo o excavación en la tierra, etc.) o calidad del servicio de agua deficitario (no contar con agua de red pública y/ o tenencia de agua fuera de la vivienda o el terreno).

- Deficitarias críticas: viviendas con ambas condiciones (la calidad del servicio sanitario y la calidad del agua) deficitarias.

Figura 4. Condición de saneamiento de la vivienda

\begin{tabular}{|c|c|c|}
\hline \multirow[b]{2}{*}{$\begin{array}{l}\text { Calidad del servicio de } \\
\text { agua }\end{array}$} & \multicolumn{2}{|c|}{ Calidad del servicio sanitario } \\
\hline & $\begin{array}{c}\text { Aceptable } \\
\text { (con baño con botón, cadena } \\
\text { o mochila para el inodoro y } \\
\text { descarga a red pública o } \\
\text { cámara séptica y pozo ciego) }\end{array}$ & $\begin{array}{c}\text { deficitario } \\
\text { (sin baño; con baño sin botón, } \\
\text { cadena o mochila para el } \\
\text { inodoro, con baño con botón, } \\
\text { cadena o mochila para el } \\
\text { inodoro y descarga sólo a } \\
\text { pozo ciego, a hoyo o } \\
\text { excavación en la tierra, etc.) }\end{array}$ \\
\hline $\begin{array}{l}\text { aceptable } \\
\text { (agua de red pública por cañería } \\
\text { dentro de la vivienda) }\end{array}$ & $\begin{array}{l}\text { CSV } \\
\text { aceptable }\end{array}$ & $\begin{array}{c}\text { CSV } \\
\text { deficitaria }\end{array}$ \\
\hline $\begin{array}{l}\text { deficitario } \\
\text { (agua de otra procedencia y/ o } \\
\text { fuera de la vivienda o el terreno) }\end{array}$ & $\begin{array}{c}\text { CSV } \\
\text { deficitaria }\end{array}$ & $\begin{array}{l}\text { CSV } \\
\text { critica }\end{array}$ \\
\hline
\end{tabular}

Fuente: elaboración propia. Realización M. Marcos.

\subsubsection{Tipo de vivienda}

El tipo de vivienda es un indicador construido en base a la pregunta censal Tipo de Vivienda particular, y permite clasificar el parque habitacional en dos categorías (Figura 5):

- Aceptables: viviendas de características aceptables (casas o departamentos)

- Deficitarias: viviendas de características deficitarias (ranchos, casillas, piezas en inquilinatos u hotelespensión, locales no construidos para habitación, viviendas móviles, espacios en la vía pública utilizados como lugar de habitación o pernocte por personas en situación de calle). 
Figura 5. Tipo de vivienda

\begin{tabular}{|c|c|}
\hline $\begin{array}{c}\text { aceptable } \\
\text { (casa/ departamento) }\end{array}$ & $\begin{array}{c}\text { deficitaria } \\
\text { (rancho/ casilla/ pieza en } \\
\text { inquilinato/ pieza en hotel } \\
\text { familiar o pensión/ local no } \\
\text { construido para } \\
\text { habitación/ vivienda móvil/ } \\
\text { personas viviendo en la } \\
\text { calle) }\end{array}$ \\
\hline TV & $\begin{array}{c}\text { TV } \\
\text { deficitaria }\end{array}$ \\
\hline
\end{tabular}

Fuente: elaboración propia. Realización: M. Marcos.

\subsubsection{Tipología de Calidad Global de la Vivienda (TCGV)}

Una vez construidas las tres tipologías parciales -la calidad material de la vivienda, la condición de saneamiento de la vivienda y el tipo de vivienda- se procede a elaborar la Tipología de Calidad Global de la Vivienda, que permitirá distinguir situaciones deficitarias que demandan reparación/mejoramiento de la vivienda existente o bien reemplazo por una nueva unidad.

Para la construcción de esta tipología, que deriva de la combinación de las tres tipologías parciales, se tuvo como criterio asignar prioridad a las dimensiones de calidad material y tipo: si una vivienda califica como irrecuperable en una o en ambas dimensiones, se la cataloga como demandante de reemplazo. La dimensión referida al saneamiento, por su parte, sólo tiene incidencia para efectos de distinguir, en algunos casos, entre situaciones aceptables y recuperables, y entre situaciones irrecuperables e irrecuperables críticas.

A partir de la TCGV, se clasifican a las viviendas en cuatro categorías (Figura 6):

- Aceptables: viviendas de materialidad, tipo y saneamiento aceptable.

- Recuperables: viviendas que reúnen las siguientes condiciones: Tipo aceptable, materialidad aceptable y saneamiento deficitario o crítico; o Tipo aceptable y materialidad recuperable, independientemente de la condición de saneamiento.

- Irrecuperables: viviendas que reúnen las siguientes condiciones: Tipo irrecuperable y materialidad aceptable, independientemente de la condición de saneamiento; o Tipo irrecuperable, materialidad recuperable y saneamiento aceptable.

- Irrecuperables críticas: viviendas que reúnen las siguientes condiciones: Materialidad irrecuperable, independientemente del tipo y saneamiento; Tipo irrecuperable, materialidad recuperable y condición de saneamiento deficitario o crítico. 
Figura 6. Calidad global de la vivienda

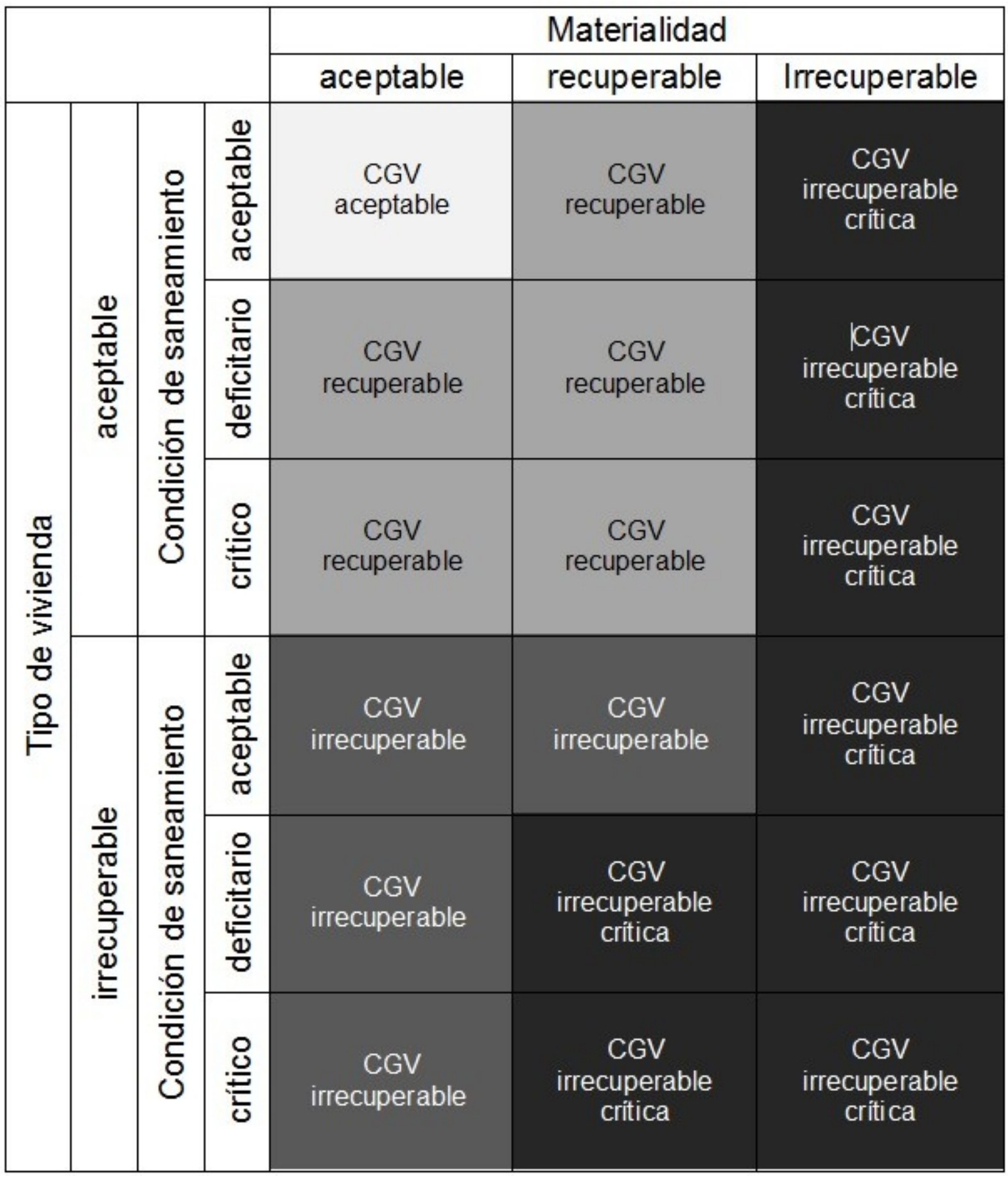

Fuente: elaboración propia. Realización: M. Marcos.

\section{Resultados y discusión}

A continuación, se realiza una aplicación de esta metodología al Municipio de Morón, $\underline{12}$ a partir de la cual se pueden constatar algunas potencialidades que presenta la forma de medición del déficit habitacional aquí desarrollada.

El Municipio de Morón forma parte de la Región Metropolitana de Buenos Aires (RMBA), que comprende a la Ciudad Autónoma de Buenos Aires y a otros 23 Partidos de la Provincia de Buenos Aires. Morón se localiza en la zona oeste de esta Región, y para el año 2010 contaba con una población de 321.109 personas (2,5\% de la 
población de la RMBA), que conforman 106.902 hogares particulares y habitan en 100.936 viviendas. Si bien es uno de los partidos que menos creció en la última década (en el 2010 contaba con 4\% más de personas que en el censo anterior de 2001), es uno de los más densos, con sus 5.734 habitantes por kilómetro cuadrado. Constituye un municipio de la primera corona o cordón de partidos que rodean a la Ciudad de Buenos Aires, y se ha consolidado como una jurisdicción donde priman condiciones socioeconómicas y habitacionales favorables respecto al conjunto de la RMBA: es uno de los municipios con menor pobreza estructural (3,7\% de hogares con Necesidades Básicas Insatisfechas) y casi un $80 \%$ de sus viviendas están construidas con materiales resistentes y sólidos en pisos y techos, lo que hace de Morón una de las jurisdicciones mejor posicionadas en lo relativo a la calidad de sus viviendas en la Región (INDEC, 2010). Sin embargo, presenta importantes heterogeneidades a su interior, que la convierten en un caso de estudio sumamente rico para aplicar la actual propuesta.

Las Figuras 7 y 8 representan la magnitud que alcanzan el déficit cuantitativo y el cualitativo en cada uno de los barrios que componen el municipio. Estas figuras ponen de manifiesto las heterogeneidades que se producen a nivel intramunicipal -en este caso se reconstruyeron los barrios, pero la base de datos del cuestionario censal básico permite procesar información para unidades geoestadísticas más pequeñas- y posibilita localizar problemáticas habitacionales específicas. En lo que refiere al déficit cuantitativo -la presencia de viviendas con problemas de materialidad severos, que requieren ser reemplazadas por nuevas unidades, o en las que conviven múltiples hogares o núcleos familiares hacinados en condiciones económicas de aspirar a una solución habitacional autónoma-, puede observarse que, si en la zona centro y norte del municipio el déficit tiende a adquirir valores bajos (con diversos barrios con menos de 10,5 viviendas a construir por cada 100 viviendas ocupadas), en la zona sur se concentran las situaciones más críticas, con casos extremos donde este valor asciende a más de 47,2. Por su parte, en relación con las viviendas que padecen algún tipo de déficit cualitativo -que presentan problemas de orden material, sanitario o son de tamaño inadecuado, pero cuyas deficiencias son subsanables mediante obras de mejoramiento y/o ampliación- también se destaca la zona central con baja incidencia del déficit (menos de 27,4\%), pero aquí las áreas más críticas se localizan en el oeste, con barrios donde más del 77\% de las viviendas requieren mejoramiento y/o ampliación.

Este panorama (territorializado) de la magnitud que alcanzan ambos componentes del déficit habitacional constituye información de gran valor para los ámbitos de gestión, permitiendo evaluar el impacto de las intervenciones realizadas y orientar futuros cursos de acción. En lo que refiere al déficit cuantitativo, pone de manifiesto que la zona sur de Morón constituye un área particularmente relegada en términos habitacionales, a ser priorizada por las políticas públicas municipales $\underline{13}$. En lo relativo al déficit cualitativo, evidencia que las zonas más críticas se localizan en el oeste, lo que en gran medida se vincula con las limitaciones en la expansión de la red de agua y de cloacas, que hacen a las condiciones de saneamiento de las viviendas. $\frac{14}{}$ En una mirada de conjunto, el análisis de datos microespaciales georreferenciados permite concluir que las zonas del Municipio que colindan al oeste con Ituzaingó y al sur con Merlo y, en menor medida, con La Matanza, constituyen zonas de intervención prioritarias, donde las carencias en materia habitacional de uno u otro tipo encuentran sus mayores niveles de extensividad entre las familias y sus viviendas. Es allí, por lo tanto, donde los esfuerzos gubernamentales para el mejoramiento del parque habitacional existente, el saneamiento del entorno de las viviendas y la construcción de nuevas unidades produciría su mayor impacto.

Para completar el diagnóstico, la Tabla 1 da cuenta de los distintos requerimientos que se desprenden de cada tipo de déficit habitacional y su localización barrial, permitiendo identificar (y cuantificar) necesidades de intervención específicas: ya sea el reemplazo de unidades de vivienda irrecuperable o la construcción de nuevas viviendas para hogares y núcleos familiares allegados (déficit cuantitativo), como la exigencia de mejoramiento y/o ampliación del parque habitacional existente (déficit cualitativo) en cada uno de los barrios que componen el municipio. 
Figura 7. Magnitud del déficit habitacional cuantitativo, según barrio. Morón, año 2010

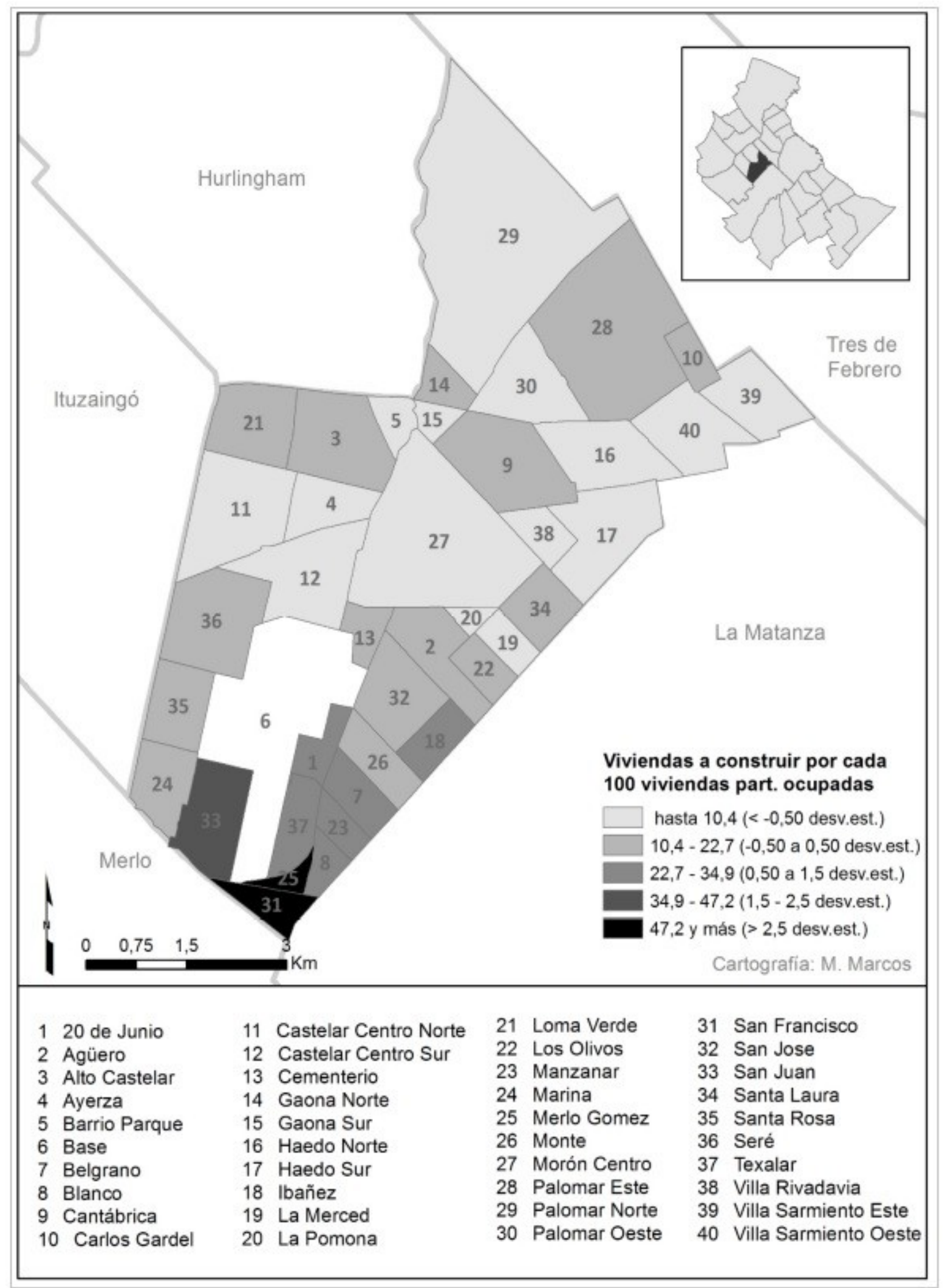

Fuente: elaboración propia en base a INDEC, Censo Nacional de Población, Hogares y Viviendas 2010 (Base de datos REDATAM y Cartografía); y Cartografía del Municipio de Morón. Procesamientos: M. Marcos, M. M. Di Virgilio y G. Mera. Cartografía: M. Marcos 
Figura 8. Magnitud del déficit habitacional cualitativo, según barrio. Morón, año 2010

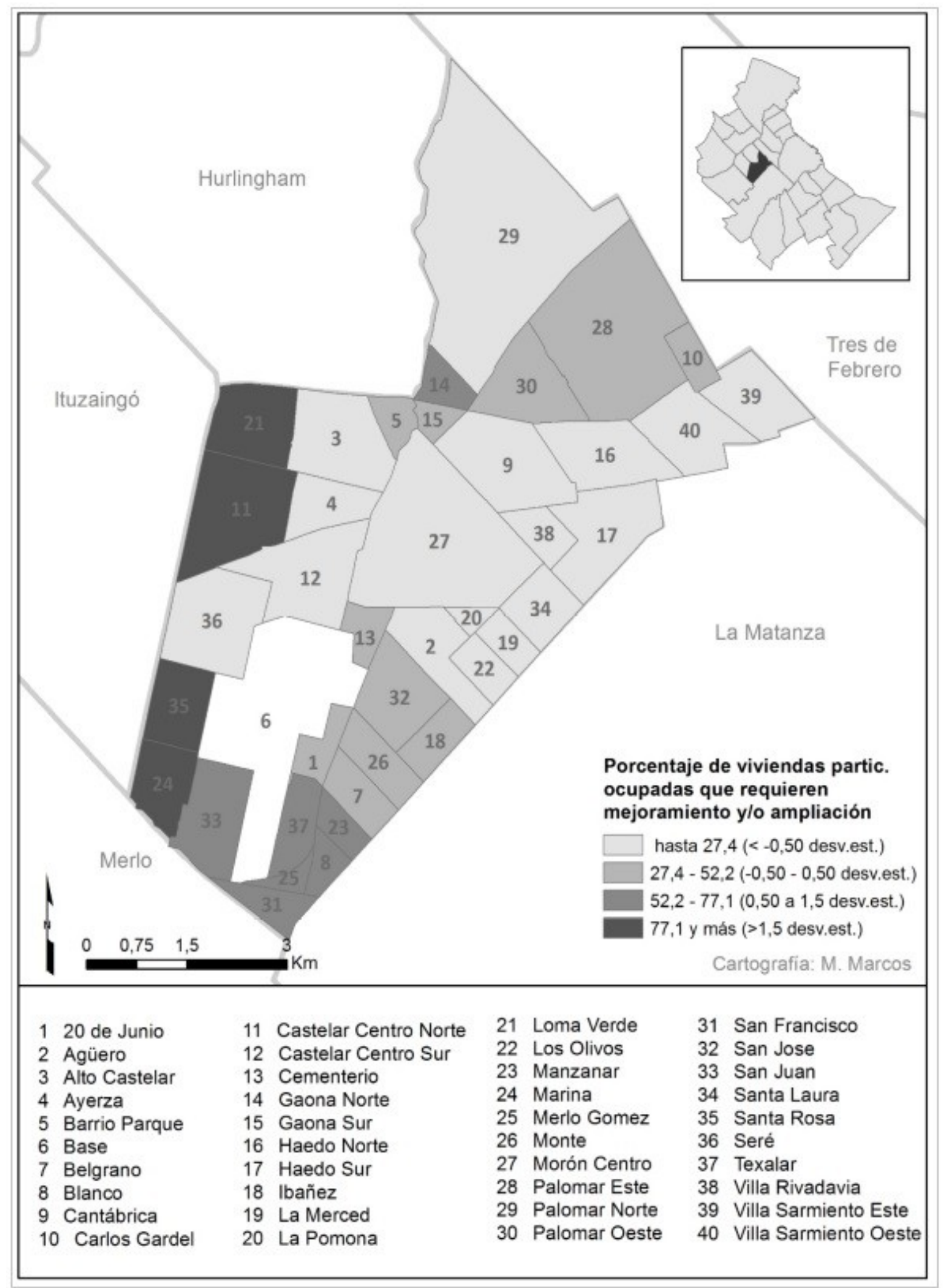

Fuente: elaboración propia en base a INDEC, Censo Nacional de Población, Hogares y Viviendas 2010 (Base de datos REDATAM y Cartografía); y Cartografía del Municipio de Morón. Procesamientos: M. Marcos, M. M. Di Virgilio y G. Mera. Cartografía: M. Marcos 
Tabla 1. Magnitud del déficit habitacional por tipo, según barrio. Morón, año 2010

\begin{tabular}{|c|c|c|c|c|c|c|c|c|}
\hline \multirow[b]{2}{*}{ Barrio } & \multicolumn{4}{|c|}{ Déficit cuantitativo } & \multicolumn{4}{|c|}{ Déficit cualitativo } \\
\hline & $\begin{array}{l}\text { Reemplazo } \\
\text { de } \\
\text { viviendas } \\
\text { irrecup. }\end{array}$ & $\begin{array}{c}\text { Nuevas } \\
\text { viviendas } \\
\text { para } \\
\text { hogares } \\
\text { allegados }\end{array}$ & $\begin{array}{l}\text { Nuevas } \\
\text { viviendas } \mathrm{p} / \\
\text { núcleos } \\
\text { secundarios } \\
\text { indep. hac. }\end{array}$ & Total & $\begin{array}{c}\text { Viviendas cl } \\
\text { necesidades } \\
\text { de } \\
\text { ampliación }\end{array}$ & $\begin{array}{l}\text { Viviendas } \mathrm{dl} \\
\text { necesidades } \\
\text { de mejoram. }\end{array}$ & $\begin{array}{l}\text { Viviendas } d \\
\text { necesidades } \\
\text { de ampliac. } \\
\text { y mejoram. }\end{array}$ & Total \\
\hline 20 de Junio & 233 & 144 & 23 & 400 & 22 & 497 & 45 & 564 \\
\hline Agüero & 86 & 237 & 20 & 343 & 39 & 571 & 28 & 637 \\
\hline Alto Castelar & 184 & 217 & 37 & 437 & 67 & 959 & 33 & 1.059 \\
\hline Ayerza & 49 & 65 & 3 & 117 & 9 & 270 & 1 & 280 \\
\hline Barrio Parque & 31 & 32 & 4 & 67 & 8 & 352 & 14 & 374 \\
\hline Base & - & - & - & - & - & - & - & - \\
\hline Belgrano & 234 & 166 & 39 & 439 & 26 & 728 & 62 & 816 \\
\hline Blanco & 218 & 79 & 24 & 322 & 1 & 671 & 50 & 722 \\
\hline Cantábrica & 104 & 135 & 11 & 250 & 21 & 432 & 13 & 466 \\
\hline Carlos Gardel & 134 & 147 & 40 & 321 & 70 & 359 & 42 & 471 \\
\hline Castelar Centro N. & 96 & 107 & 3 & 206 & 6 & 3.507 & 14 & 3.526 \\
\hline Castelar Centro S. & 91 & 139 & 13 & 243 & 39 & 540 & 16 & 595 \\
\hline Cementerio & 25 & 80 & 6 & 111 & 15 & 208 & 18 & 241 \\
\hline Gaona Norte & 52 & 53 & 8 & 113 & 9 & 298 & 17 & 324 \\
\hline Gaona Sur & 20 & 20 & 7 & 47 & 7 & 192 & 5 & 204 \\
\hline Haedo Norte & 53 & 118 & 2 & 173 & 19 & 313 & 3 & 335 \\
\hline Haedo Sur & 69 & 193 & 14 & 276 & 37 & 499 & 18 & 554 \\
\hline lbañez & 347 & 161 & 41 & 549 & 21 & 557 & 60 & 638 \\
\hline La Merced & 29 & 40 & 10 & 79 & 27 & 216 & 13 & 256 \\
\hline La Pomona & 8 & 15 & 0 & 23 & 3 & 66 & 4 & 73 \\
\hline Loma Verde & 153 & 177 & 17 & 347 & 0 & 2.509 & 58 & 2.566 \\
\hline Los Olivos & 57 & 84 & 11 & 152 & 28 & 253 & 20 & 301 \\
\hline Manzanar & 190 & 116 & 16 & 322 & 5 & 580 & 36 & 621 \\
\hline Marina & 223 & 136 & 35 & 394 & 0 & 1.696 & 76 & 1.772 \\
\hline Merlo Gomez & 86 & 65 & 14 & 165 & 0 & 228 & 23 & 251 \\
\hline Monte & 182 & 174 & 34 & 389 & 41 & 730 & 56 & 827 \\
\hline Morón Centro & 381 & 261 & 54 & 696 & 193 & 1.636 & 52 & 1.881 \\
\hline Palomar Este & 392 & 654 & 87 & 1.133 & 126 & 3.254 & 131 & 3.511 \\
\hline Palomar Norte & 59 & 104 & 8 & 171 & 31 & 511 & 13 & 555 \\
\hline Palomar Oeste & 122 & 143 & 18 & 283 & 16 & 1.072 & 25 & 1.113 \\
\hline San Francisco & 404 & 217 & 36 & 656 & 0 & 827 & 87 & 914 \\
\hline San Jose & 216 & 337 & 57 & 611 & 51 & 1.178 & 65 & 1.294 \\
\hline San Juan & 797 & 214 & 79 & 1.090 & 0 & 1.878 & 136 & 2.014 \\
\hline Santa Laura & 102 & 135 & 19 & 256 & 30 & 409 & 25 & 464 \\
\hline Santa Rosa & 181 & 73 & 16 & 270 & 0 & 1.200 & 54 & 1.254 \\
\hline Seré & 193 & 221 & 19 & 433 & 30 & 835 & 31 & 896 \\
\hline Texalar & 338 & 241 & 25 & 604 & 20 & 1.306 & 61 & 1.387 \\
\hline Villa Rivadavia & 10 & 21 & 2 & 33 & 5 & 71 & 2 & 78 \\
\hline Villa Sarmiento E. & 46 & 118 & 6 & 170 & 20 & 304 & 14 & 338 \\
\hline Villa Sarmiento 0. & 70 & 113 & 9 & 192 & 30 & 341 & 10 & 381 \\
\hline Total & 6.264 & 5.752 & 866 & 12.882 & 1.072 & 32.051 & 1.431 & 34.554 \\
\hline
\end{tabular}

Fuente: elaboración personal en base a INDEC. Censo Nacional de Población, Hogares y Viviendas 2010. Base de datos REDATAM. Procesamientos: M. Marcos, M. M. Di Virgilio y G. Mera. 
El abordaje metodológico desarrollado brinda interesantes posibilidades analíticas tanto para campo académico como para el campo político y social. Por un lado, en la medida que se trata de una propuesta integral, que trasciende la mirada más clásica del déficit vinculada con la materialidad de la vivienda, para incorporar: a) la dimensión socioeconómica, relacionada con las posibilidades económicas de los hogares para afrontar arreglos residenciales de otro tipo, y b) la dimensión demográfica, asociada con la estructura de los hogares, permitiendo identificar requerimientos habitacionales vinculados con la composición interna de los hogares (por presencia de múltiples núcleos familiares), su tamaño (y la posible inadecuación del tamaño de la vivienda para albergarlos con comodidad) y/o la presencia de estrategias residenciales (como la presencia de varios hogares compartiendo vivienda) que requieren una solución habitacional autónoma. Y, por otro lado, en la medida que remite a una concepción abarcativa del déficit habitacional, que contempla tanto su dimensión cuantitativa como su dimensión cualitativa.

La propuesta desarrollada por el MINVU abre, así, un campo de análisis sumamente rico para los estudios preocupados por el problema del hábitat y la posibilidad de desarrollar diagnósticos integrales que sirvan de insumo para orientar políticas de intervención dirigidas al mejoramiento de las condiciones de vida de las poblaciones, en particular de los grupos más vulnerables.

La adecuación de ese trabajo desarrollada aquí se propuso contribuir a esta línea de estudios, brindando las herramientas necesarias para implementar esta metodología en el contexto argentino, para lo cual debieron realizarse diversas modificaciones, vinculadas tanto con las características propias del parque habitacional local como con las posibilidades y limitaciones que plantea el último censo de población como fuente de datos. A modo de síntesis, los principales cambios operados respecto a la propuesta original remitieron a:

(i) adaptaciones por falta de alguna pregunta censal en el cuestionario básico del censo o por la menor desagregación de alguna categoría de respuesta. Dentro del primer caso puede mencionarse la ausencia de variables como: a) los materiales constructivos de las paredes de las viviendas (para calcular la tipología de calidad material de la vivienda), elemento que debió ser excluido de los procesamientos; b) la situación conyugal de las personas (para el cálculo del allegamiento interno), por lo que no se pudieron identificar los posibles núcleos de hijos/as no solteros/as, lográndose una aproximación menos exacta a los núcleos de hijas madres solteras; y c) la percepción de ingresos por jubilación o rentas (para el cálculo de la dependencia económica), por lo que la cantidad de jubilados debió inferirse a partir de la edad de las personas y los rentistas quedaron excluidos como perceptores. En el segundo caso, puede mencionarse la menor desagregación en las categorías de respuesta de la relación de parentesco (fundamental para el cálculo del allegamiento interno de los hogares), lo que impidió la identificación de los núcleos de hermanos o cuñados.

(ii) Modificaciones de algunos criterios clasificatorios por motivos conceptuales. En este caso se encuentra: a) el cálculo del allegamiento interno de los hogares, para el cual se decidió no contabilizar como núcleos independientes a los grupos de otros parientes y otros no parientes del jefe del hogar, puesto que se desconoce el vínculo entre ellos; y b) una situación de déficit cualitativo para los autores chilenos, que aquí no se la considera tal: cuando se producen situaciones que conjugan la presencia de hogares con allegamiento externo y/o núcleos allegados independientes, materialidad aceptable y hacinamiento, en esta propuesta la vivienda no debe incluirse dentro de las demandantes de ampliación (déficit cualitativo), dado que la construcción de una nueva vivienda para resolver la situación de los hogares y/o núcleos allegados- probablemente reduzca los niveles de hacinamiento del hogar que permanezca en la vivienda original.

(iii) Ajustes orientados a compatibilizar los criterios metodológicos con las convenciones académicas argentinas. Dentro de las modificaciones realizadas con este criterio puede mencionarse: a) el cálculo del hacinamiento, para el que se siguió la definición operacional del INDEC, que pone en relación la cantidad de personas en el hogar y la cantidad de cuartos de uso exclusivo en el hogar (mientras que la propuesta del MINVU trabaja con la información de personas en la vivienda y habitaciones usadas para dormir en la vivienda, sin considerar que sean de uso exclusivo del hogar); y b) el limite trazado entre las viviendas de tipo aceptable y las deficitarias en el 
cálculo del tipo de vivienda, considerando como aceptables sólo a las casas y los departamentos (mientras que en la propuesta del MINVU son aceptables también las “piezas en casa antiguas o conventillos”, equivalentes a las piezas en inquilinatos, hoteles familiares y pensiones argentinos, históricamente considerados como un tipo de vivienda deficitaria).

(iv) Incorporación de nuevas variables para lograr mayor precisión en la construcción de algunos indicadores. En este grupo puede mencionarse: a) la condición de saneamiento, en cuyo caso la batería de variables disponible en el cuestionario básico del censo argentino supera a la del censo chileno, tanto para relevar el servicio sanitario de las viviendas (indagando de manera separada si los hogares tienen baño o letrina, si este cuenta con descarga de agua y cuál es su sistema de desagüe), como el servicio de agua (indagando tanto por la provisión como por la procedencia del agua para beber y cocinar), lo que permitió identificar las condiciones de saneamiento con mayor precisión que en la propuesta original; y b) la calidad material de la vivienda, incorporando a la construcción de la tipología información acerca del revestimiento interior o cielorraso del techo (no contemplado en la propuesta del MINVU), ganándose precisión a la hora de distinguir techos de diferente calidad.

(v) Mayor desagregación en las categorías de algunas tipologías -como en el caso de la Condición de Saneamiento de la vivienda y de la Calidad Global de la Vivienda- que permite distinguir situaciones aceptables, recuperables y deficitarias/ irrecuperables, pero también, dentro de estas últimas, la identificación de situaciones críticas.

Finalmente, y vinculado con las potencialidades analíticas que brinda esta última modificación, la actual propuesta tuvo entre sus premisas incorporar la posibilidad de identificar situaciones que demandan distintos tipos de intervención y que tienen diferentes niveles de criticidad, lo que constituye un fundamental aporte para las políticas públicas, estableciendo prioridades orientativas para las intervenciones territoriales concretas.

La Figura 9 sintetiza las posibilidades que emergen en este sentido. Puede verse allí cómo la combinación de los diversos determinantes del déficit habitacional permite identificar situaciones que demandan intervenciones diferentes -ya sea la ampliación de la vivienda existente, su mejoramiento, el reemplazo de la unidad y/o la construcción de viviendas adicionales-, así como también el nivel de prioridad en la intervención que exige cada caso, en una gradiente de contempla la existencia de situaciones más apremiantes que otras por la criticidad de las condiciones habitacionales en las que se encuentran los hogares, o por la sumatoria de diversos tipos de déficits, que agrava el estado en el que se hallan y demanda soluciones más inmediatas. 
Figura 9. Tipo y áreas prioritarias de intervención según los determinantes operativos del déficit habitacional

\begin{tabular}{|c|c|c|c|c|c|c|c|}
\hline \multicolumn{2}{|c|}{ Cond. alleg. } & \multirow{2}{*}{$\begin{array}{l}\text { Dep. } \\
\text { econ. }\end{array}$} & \multirow{2}{*}{$\begin{array}{l}\text { Condición de } \\
\text { hacinarriento }\end{array}$} & \multicolumn{4}{|c|}{ Materialidad de la vivienda } \\
\hline Ext. & Irt. & & & Aceptable & Recuperable & Irrecuper able & Irrecuper able crítica \\
\hline \multirow{9}{*}{ 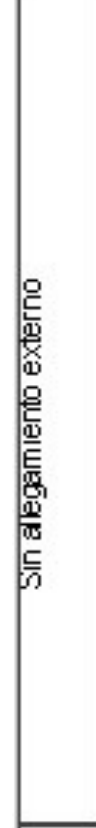 } & \multirow{3}{*}{ 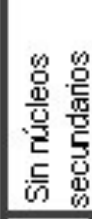 } & & Sin hacinam. & sin requerimientos & mejorarrierto & reemplazo de vivienda & reermplazo de vivienda \\
\hline & & & Medio & ampliación & $\begin{array}{l}\text { mejorarriento + } \\
\text { amplación }\end{array}$ & reemplazo de vivienda & reerrplazo de vivienda \\
\hline & & & Crtico & ampliación & $\begin{array}{c}\text { mejorarriento + } \\
\text { amplación }\end{array}$ & reernplazo de vivienda & reerrplazo de vivienda \\
\hline & \multirow{6}{*}{ 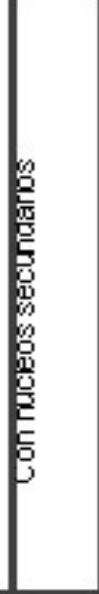 } & \multirow{3}{*}{ 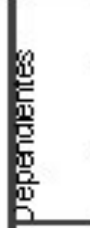 } & Sin hacinam. & sin requerimientos & mejorarrierto & reemplazo de vivienda & reermplazo de vivienda \\
\hline & & & Medo & ampliación & $\begin{array}{c}\text { mejorarriento + } \\
\text { amplación }\end{array}$ & reemplazo de vivienda & reermplazo de vivienda \\
\hline & & & Crtico & ampliación & $\begin{array}{c}\text { mejorarriento + } \\
\text { amplación }\end{array}$ & reemplazo de vivienda & reerrplazo de vivienda \\
\hline & & \multirow{3}{*}{ 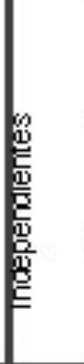 } & Sin hacinam. & $\begin{array}{c}\text { requer iniento }>=1 \\
\text { vivenda }\end{array}$ & $\begin{array}{c}\text { mejor aniento de vivi. } \\
+ \text { requermiento }>=1 \\
\text { vivenda }\end{array}$ & $\begin{array}{c}\text { reemplazo de vivienda } \\
+ \text { requerimierto }:=1 \\
\text { vivenda }\end{array}$ & $\begin{array}{c}\text { reermplazo de vivienda } \\
+ \text { requer iniento }:=1 \\
\text { vivenda }\end{array}$ \\
\hline & & & Medio & $\begin{array}{c}\text { requer iniento }:=1 \\
\text { vivenda }\end{array}$ & $\begin{array}{c}\text { requerimiento }=1 \\
\text { vivenda }\end{array}$ & $\begin{array}{c}\text { reemplazo de vivienda } \\
+ \text { requerimierto }:=1 \\
\text { vivenda }\end{array}$ & $\begin{array}{c}\text { reermplazo de vivienda } \\
+ \text { requer iniento }:=1 \\
\text { vivenda }\end{array}$ \\
\hline & & & Crtico & $\begin{array}{c}\text { requer iniento }>=1 \\
\text { vivenda }\end{array}$ & $\begin{array}{c}\text { requerimiento }=1 \\
\text { vivenda }\end{array}$ & $\begin{array}{c}\text { reemplazo de vivienda } \\
+ \text { requerimierto }:=1 \\
\text { vivenda }\end{array}$ & $\begin{array}{c}\text { reermplazo de vivienda } \\
+ \text { requer iniento }>=1 \\
\text { vivenda }\end{array}$ \\
\hline \multirow{9}{*}{ 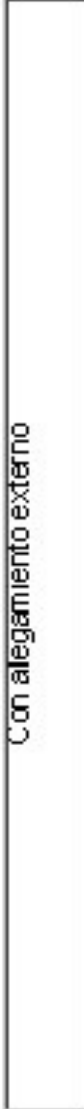 } & \multirow{3}{*}{ 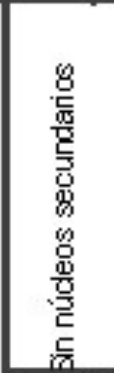 } & & Sin hacinam. & $\begin{array}{c}\text { requer iniento }>=1 \\
\text { vivenda }\end{array}$ & $\begin{array}{c}\text { mejor arrierto de viv. }+ \\
\text { requerimiento }==1 \\
\text { vivenda }\end{array}$ & $\begin{array}{c}\text { reemplazo de vivienda } \\
\text { + requerimierto }>=1 \\
\text { vivenda }\end{array}$ & $\begin{array}{c}\text { reermplazo de vivienda } \\
+ \text { requer iniento }>=1 \\
\text { vivenda }\end{array}$ \\
\hline & & & Medo & $\begin{array}{c}\text { requer iniento }==1 \\
\text { vivenda }\end{array}$ & $\begin{array}{c}\text { requerimiento }=1 \\
\text { vivenda }\end{array}$ & $\begin{array}{c}\text { reemplazo de vivienda } \\
+ \text { requerimierto }:=1 \\
\text { vivienda }\end{array}$ & $\begin{array}{c}\text { reerrplazo de vivienda } \\
+ \text { requer iniento }>=1 \\
\text { vivenda }\end{array}$ \\
\hline & & & Crtico & $\begin{array}{c}\text { requer iniento }==1 \\
\text { vivenda }\end{array}$ & $\begin{array}{c}\text { requerimiento }==1 \\
\text { vivenda }\end{array}$ & $\begin{array}{c}\text { reemplazo de vivienda } \\
+ \text { requerimierto }==1 \\
\text { vivenda }\end{array}$ & $\begin{array}{c}\text { reermplazo de vivienda } \\
+ \text { requer iniento }>=1 \\
\text { vivenda }\end{array}$ \\
\hline & \multirow{6}{*}{ 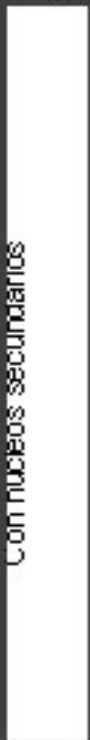 } & \multirow{3}{*}{ 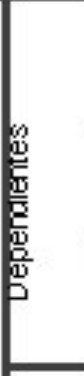 } & Sin hacinam. & $\begin{array}{c}\text { requer iniento }>=1 \\
\text { vivenda }\end{array}$ & $\begin{array}{c}\text { mejor arrierto de viv. + } \\
\text { requerimiento }:=1 \\
\text { vivenda }\end{array}$ & $\begin{array}{c}\text { reemplazo de vivienda } \\
+ \text { requerimierto }==1 \\
\text { vivenda }\end{array}$ & $\begin{array}{c}\text { reermplazo de vivienda } \\
+ \text { requer iniento }>=1 \\
\text { vivenda }\end{array}$ \\
\hline & & & Medo & $\begin{array}{c}\text { requer iniento }>=1 \\
\text { vivenda }\end{array}$ & $\begin{array}{c}\text { requerimiento }=1 \\
\text { vivenda }\end{array}$ & $\begin{array}{c}\text { reemplazo de vivienda } \\
+ \text { requerimierto }==1 \\
\text { vivenda }\end{array}$ & $\begin{array}{c}\text { reermplazo de vivienda } \\
\text { + requer iniento }=1 \\
\text { vivenda }\end{array}$ \\
\hline & & & Crtico & $\begin{array}{c}\text { requer iniento }>=1 \\
\text { vivenda }\end{array}$ & $\begin{array}{c}\text { requerimiento }=1 \\
\text { vivenda }\end{array}$ & $\begin{array}{c}\text { reemplazo de vivienda } \\
+ \text { requerimierto }:=1 \\
\text { vivenda }\end{array}$ & $\begin{array}{c}\text { reerrplazo de vivienda } \\
+ \text { requer iniento }:=1 \\
\text { vivenda }\end{array}$ \\
\hline & & \multirow{3}{*}{ 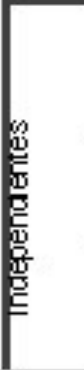 } & Sin hacinam. & $\begin{array}{c}\text { requer iniento }>=1 \\
\text { vivenda }\end{array}$ & $\begin{array}{c}\text { mejor arrierto de viv. }+ \\
\text { requerimiento }:=2 \\
\text { viviendas }\end{array}$ & $\begin{array}{c}\text { reemplazo de vivienda } \\
+ \text { requerimierto }:=1 \\
\text { vivenda }\end{array}$ & $\begin{array}{c}\text { reerrplazo de vivienda } \\
+ \text { requer iniento }:=1 \\
\text { vivenda }\end{array}$ \\
\hline & & & Medo & $\begin{array}{c}\text { requer iniento }>=1 \\
\text { vivenda }\end{array}$ & $\begin{array}{c}\text { requerimiento }=1 \\
\text { vivenda }\end{array}$ & $\begin{array}{c}\text { reemplazo de vivienda } \\
\text { + requerimierto }==2 \\
\text { viviendas }\end{array}$ & $\begin{array}{c}\text { reermplazo de vivienda } \\
+ \text { requer iniento }>=2 \\
\text { viviendes }\end{array}$ \\
\hline & & & Crtico & $\begin{array}{c}\text { requer iniento } s=2 \\
\text { vivienclas }\end{array}$ & $\begin{array}{c}\text { requerimiento }=2 \\
\text { viviendas }\end{array}$ & $\begin{array}{c}\text { reemplazo de vivienda } \\
+ \text { requerimierto }:=2 \\
\text { viviendas }\end{array}$ & $\begin{array}{c}\text { reerrplazo de vivienda } \\
+ \text { requer iniento }>=2 \\
\text { viviendas }\end{array}$ \\
\hline
\end{tabular}

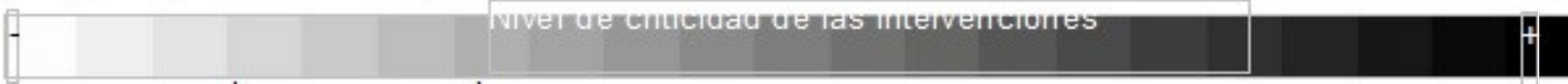

Fuente: elaboración propia. Realización: M. Marcos. 
Sobre este cuadro de situación sería importante incorporar, de cara a estudios futuros, la posibilidad de identificar escenarios prioritarios vinculados con la presencia en los hogares de poblaciones específicas, más propensas a padecer situaciones de vulnerabilidad -como adultos mayores, personas con discapacidad, ciertos perfiles migratorios, entre otros- que puedan requerir de intervenciones particulares desde la política pública.

\section{Conclusiones}

El trabajo se propuso ensayar una estrategia de medición del déficit habitacional que diera cuenta integralmente de sus dimensiones. La medida a desarrollar debía permitir, por un lado, dimensionar el problema con mayor precisión y, por el otro, comprender la distribución del déficit en el territorio y evaluar el impacto de intervenciones públicas en áreas de interés para la gestión local. Para cumplir con estos requisitos, y siguiendo con las recomendaciones que la bibliografía hace acerca de las fuentes que se revelan como más adecuadas para la tarea, la presente propuesta se abocó al trabajo con los microdatos del último Censo Nacional de Población y Vivienda del año 2010. En la construcción de la medida se trabajó exclusivamente con datos del cuestionario censal básico. El cuestionario censal básico ofrece información sobre un número reducido de variables, lo que introdujo limitaciones en la cantidad y el tipo de indicadores utilizados en el diseño de la propuesta. Sin embargo, esa decisión es la que permite alcanzar una medición del déficit con altos niveles de desagregación espacial. Este constituye, a nuestro entender, uno de los aportes más significativos del ejercicio.

La propuesta, a su vez, se apoya en un tratamiento extenso de indicadores que, combinados en tipologías simples, permiten dar cuenta de las diferentes dimensiones del déficit habitacional: cualitativa y cuantitativa. En este sentido, la propuesta prevé un abordaje integral del fenómeno que intenta superar las limitaciones vinculadas con la falta de integralidad y completud de las medidas. No obstante, cada uno de los indicadores complejos que sirven de base a su elaboración, pueden ser utilizados y aplicados como medidas independientes que permiten mensurar cada una de las dimensiones en sí.

A partir de la posibilidad de georreferenciar los resultados, la propuesta genera condiciones para superar el reduccionismo viviendista (Fernández Wagner, 2004) que escinde la problemática del déficit habitacional de los entornos urbanos en los que se localiza y de los procesos socioespaciales los caracterizan.

De este modo, la propuesta no sólo provee una herramienta para la medición integral del déficit, sino que permite mensurar: 1) la condición de allegamiento externo, 2) la condición de allegamiento interno, 3) la dependencia económica, 4) la condición de hacinamiento, y 5) la calidad de la vivienda, teniendo en cuenta su calidad material, la condición de saneamiento y el tipo.

La medida se reveló apta, también, para identificar dos cuestiones clave, directamente vinculadas con la medición del déficit habitacional y con la gestión pública del problema: el tipo de intervenciones que requiere y la prioridad de las mismas. De este modo, no sólo permite identificar el problema a escala micro-espacial, sino que además constituye un instrumento apto para discriminar el tipo de política que resulta ser más adecuada para solucionarlo: la ampliación de la vivienda existente, su mejoramiento, el reemplazo de la unidad y/o la construcción de viviendas adicionales. Asimismo, resultó una medida útil para identificar los niveles de criticidad del problema y la definición de prioridades de las intervenciones. De este modo, la propuesta respondió a la multiplicidad de inquietudes intelectuales que impulsaron: aportar al conocimiento producido en relación a la cuestión del déficit habitacional y, sobre todo, ofrecer una herramienta útil para la gestión y la intervención en el ámbito público respetando los estándares de la producción académica.

A pesar de ello, no es posible finalizar este ejercicio sin plantear reflexivamente algunas prevenciones que colaboren con una lectura prudente de los "números". En este sentido, vale la pena recordar que la bibliografía sobre hábitat popular, en general, y estrategias habitacionales, en particular, documentan in extenso que la satisfacción de las necesidades de vivienda está sujeta a procesos dinámicos -como son las capacidades económicas de las familias, el acceso a recursos de los programas sociales, la participación en redes de ayuda 
mutua y en organizaciones de base territorial, entre otros- cuya significación y peso a nivel local es necesario evaluar a fin de comprender cabalmente los requerimientos de vivienda. De hecho, la existencia de redes de ayuda mutua y de organizaciones de base territorial puede marcar diferencias significativas en la implementación y el alcance de la política habitacional local, sea esta de obra nueva o de mejoramiento. Sin lugar a dudas, estas cuestiones han de ser ponderadas a fin de caracterizar la demanda desde un enfoque integral y territorial.

\section{Notas}

1 Las autoras agradecen especialmente los comentarios de los/as evaluadores/as anónimos/as y las sugerencias realizadas para mejorar el texto.

2 Más aún en el caso de los hogares (unidades que se pueden considerar demandantes de vivienda), cuyo ritmo de crecimiento en el período intercensal 2001-2010 (2,1\%) duplicó al de las personas (1,1\%) a nivel del total del país y llegó a triplicarlo en la Ciudad Autónoma de Buenos Aires (datos de elaboración personal en base a INDEC, Censo Nacional de Población, Hogares y Viviendas 2001 y 2010). Un análisis del impacto que estos cambios tuvieron en la demanda habitacional para la Ciudad de Buenos Aires puede leerse en Di Virgilio (2015).

$\underline{3}$ Por ejemplo, a nivel internacional, el artículo 11 del Pacto Internacional de Derechos Económicos, Sociales y Culturales consagra el derecho a una vivienda adecuada. Asimismo, el Plan de Acción Regional de América Latina y el Caribe sobre Asentamientos Humanos reconoció la importancia de las políticas de vivienda y la necesidad de aumentar las soluciones habitacionales de forma proporcional a los nuevos hogares (Arriagada, 2005). En el plano nacional, el artículo 14-bis de la Constitución argentina consagra el derecho que tienen todos los habitantes de nuestro país a una vivienda digna y de calidad y la cláusula 31 de la Constitución de la Ciudad Autónoma de Buenos Aires plantea la obligatoriedad del poder público de generar las condiciones de acceso y el goce del derecho a la vivienda adecuada.

4 Por ejemplo, el equipo del Observatorio del Conurbano Bonaerense, de la Universidad Nacional de General Sarmiento (Argentina), propone dos medidas del déficit habitacional. Por un lado, una que releva el déficit habitacional cuantitativo compuesto y que se define por la relación numérica entre viviendas y hogares, y por la residencia en viviendas de tipo irrecuperable. Por el otro, el déficit cualitativo de vivienda que refiere a la situación de hogares que habitan en viviendas cuyas condiciones de estado y localización requieren reparaciones, mejoras o completamiento. A diferencia del déficit cuantitativo, el déficit cualitativo estima la cantidad de viviendas recuperables. Tal y como se puede observar, ambas medidas se focalizan en la medición de la calidad de la vivienda y su relación con la cantidad de hogares que la habitan. Véase http://observatorioconurbano.ungs.edu.ar/?page id=2691\#Vivienda

$\underline{5}$ En países en los que no existe información disponible respecto de estos tres componentes de la vivienda se utiliza una aproximación basada en los datos existentes, tomando en consideración solamente el techo y/o las paredes o el suelo y las paredes. Sobre la base de estas combinaciones, se establecen grados de calidad constructiva. La Categoría I comprende a las viviendas construidas con materiales de mejor calidad, por desarrollarse con base en materiales más resistentes. Esta Categoría no presenta ningún tipo de déficit. En el otro extremo está la Categoría III, que incluye las viviendas construidas con los materiales más precarios. Habitualmente, se considera suficiente para que la vivienda sea considerada deficitaria que alguno de sus componentes (techo, paredes o pisos) sea de material precario. Entre ambas categorías se encuentra la II, que agrupa a las viviendas construidas con materiales de construcción sólidos pero de menor calidad o bien a partir de la combinación entre materiales de buena calidad y otros no tan buenos. Esta categoría concentra viviendas que presentan déficit cualitativo por ser de calidad insuficiente. En síntesis, se considera que el déficit cuantitativo incluye a los hogares que comparten una vivienda y a aquellos que ocupan viviendas constructivamente irrecuperables (Categoría III) (Szalachman, 2000). 
$\underline{6}$ Su definición "variará en cada país, en cada momento de su desarrollo histórico, en función de la capacidad productiva del sector de la vivienda, de las condiciones de explotación de la fuerza de trabajo, del mercado de trabajo, de las luchas del proletariado, etc.” (Pradilla, 1982, p. 311). Tal como señala Coulomb (s/f), la definición de aquello que se considera como vivienda adecuada debe analizarse como una construcción histórica, que no puede escindirse del complejo proceso de evolución de los contextos políticos, socioeconómicos y urbanos.

Z Jolly (2004), también con base en el tipo de déficit, ensaya otra tipología posible de intervenciones: políticas públicas de vivienda de Tipo I, que tienen que ver con el déficit cualitativo de vivienda (mejoramiento de casas y de barrios, reasentamientos); las de Tipo II, referidas al déficit cuantitativo de vivienda (construcción de vivienda nueva); las que tienen que ver con la dotación de suelos urbanizables, de Tipo III y, finalmente, las que "tienen que ver con el entorno (barrio, localidad) y el contorno (equipamientos metropolitanos) urbano, o política pública de vivienda (hábitat) de Tipo IV.

8 Un análisis de cómo interactúan ambas dimensiones en el caso de la Ciudad Autónoma de Buenos Aires puede leerse en Di Virgilio (2015). Para el Área Metropolitana de Buenos Aires, véase Di Virgilio, Rodríguez y Mera (2016).

$\underline{9}$ No se desconocen aquí las limitaciones que introducen la periodicidad de los relevamientos censales ni el carácter estático de la información que proveen vis a vis el carácter dinámico de la demanda habitacional y, por ende, del déficit habitacional. En este sentido, se debe recordar que los datos producidos en el marco de este artículo constituyen estimaciones -inexactas, como toda estimación, pero fundamentales para abordar la problemática desde las políticas públicas-, que pueden ser complementadas con proyecciones de la demanda habitacional basadas en el ritmo de crecimiento de los hogares y la evolución de su estructura. Finalmente, vale resaltar que los cambios en las estructuras de población y los hogares son fuertemente inerciales.

10 Cuando se producen situaciones que conjugan la presencia hogares con allegamiento externo y/o núcleos allegados independientes, materialidad aceptable y hacinamiento, la vivienda no debe incluirse dentro de las demandantes de ampliación (déficit cualitativo); esto dado a que la construcción de una nueva vivienda -para resolver la situación de los hogares y/o núcleos allegados- probablemente reduzca los niveles de hacinamiento del hogar que permanezca en la vivienda original.

$11 \mathrm{Al}$ respecto, Mabel Ariño sostiene que "no se puede establecer si los integrantes de las familias extensas y compuestas que no forman parte de ese núcleo están ligados entre sí por matrimonio, filiación o adopción” (2007, p. 276), con lo cual estos núcleos familiares secundarios permanecen "ocultos” en esas categorías censales.

$\underline{12}$ Este municipio fue seleccionado como estudio de caso en el proyecto "Diagnóstico del déficit habitacional en el Municipio de Morón: una construcción conjunta de herramientas para mejorar la gestión" (Proyecto de Extensión Universitaria y Vinculación Comunitaria "Universidad, Estado Y Territorio" de la Secretaría de Políticas Universitarias del Ministerio de Educación. Directora Dra. María Mercedes Di Virgilio).

$\underline{13}$ El Municipio de Morón, a través de la Subsecretaría para la Producción Social del Hábitat, ha impulsado acciones tendientes a la construcción de vivienda nueva en otras zonas del municipio, como la urbanización de la ex villa Carlos Gardel (en el barrio Carlos Gardel, el norte del municipio) y la construcción de viviendas en los terrenos de la Base Aérea de Morón (en el barrio Seré, en el sudoeste). (Municipio de Morón, 2009).

14 A comienzos de la década del 2000, la red de agua abarcaba buena parte del municipio, pero excluía a diversos barrios en el sur y oeste. En lo que refiere al desagüe cloacal, la red cubría solo a la zona central, dejando sin servicio a una significativa cantidad de barrios, tanto en el sur y oeste como en la zona norte de Morón. Entre el año 2007 y 2015 se amplió la cobertura de ambos servicios, pero en la actualidad aún restan áreas, en el sur y el oeste (y en el norte, en el caso de las cloacas), sin acceso a estos servicios básicos de saneamiento (Aysa, 2015). 


\section{Bibliografía}

ANSES (2010). Boletín Previsional y de la Seguridad Social 2010. Observatorio de la Seguridad Social, Buenos Aires. Recuperado de http://observatorio.anses.gob.ar/archivos/documentos/Bolet\%C3\%ADn\%20Anual \%202010.pdf

Ariño, M. (2007). Familias tradicionales, nuevas familias. En: S. Torrado (comp.). Población y Bienestar en la Argentina del primero al segundo Centenario (pp. 255-285). Buenos Aires: Edhasa.

Arriagada, C. (2003). América Latina: información y herramientas sociodemográficas para analizar y atender el déficit habitacional (Vol. 45). United Nations Publications.

Arriagada, C. (2005). El déficit habitacional en Brasil y México y sus dos megaciudades globales: estudio con los censos de 1990 y 2000. Santiago de Chile: Centro Latinoamericano de Demografía (CELADE).

Arriagada, C. (2011). Evaluación de la experiencia censal reciente sobre vivienda y hogar. Santiago de Chile: Centro Latinoamericano de Demografía (CELADE).

Arriagada, C. y Moreno, J. (2007). Medición del Déficit Habitacional: Guía práctica para calcular requerimientos cuantitativos y cualitativos mediante información censal. Santiago de Chile: Ministerio de Vivienda y Urbanismo.

AYSA (2015). Informe anual 2015. Agua y Saneamientos Argentinos S.A. Recuperado de http://www.aysa.com.ar/index.php?id seccion=1117

CELADE (1996). Déficit habitacional y datos censales sociodemográficos: una metodología. Santiago de Chile: Centro Latinoamericano de Demografía (CELADE).

Coulomb, R. (s/f). Las políticas habitacionales de los estados latinoamericanos. Ciudad de México: UAMAzcapotzalco.

Di Virgilio, M. M. (2015). Vivir en la ciudad de la furia. Ciencias Sociales, Revista de la Facultad de Ciencia Sociales, (87), 12-17.

Di Virgilio, M, Rodríguez, C. y Mera, G. (2016). La vivienda un problema persistente: las condiciones habitacionales en el área metropolitana de Buenos Aires, 1991-2010. Revista CIS, (20), 21-48.

Fernández Wagner, R. (2004). Construcción y deconstrucción histórica de lo social en el acceso a los bienes y servicios del hábitat. Revista INVI, (50), 11-20.

Fresneda, O. (1997). Magnitud del déficit habitacional en Colombia. Desarrollo Urbano en Cifras, 3.

Galvis, L.A. (2011). Geografía del déficit de vivienda urbano: Los casos de Barranquilla y Soledad. Documentos de Trabajo Sobre Economía Regional. Cartagena: Centro de Estudios Económicos Regionales (CEER).

Herzer, H. y Di Virgilio, M.M. (2011). Las necesidades habitacionales en la Ciudad de Buenos Aires: ¿Quiénes, cuántos, cómo y por qué? Realidad Económica, (262), 131-158.

INDEC (2001). Censo Nacional de Población, Hogares y Viviendas 2001. Aspectos metodológicos del Censo 2001. Recuperado de http://www.indec.mecon.ar/micro sitios/webcenso/index.asp

INDEC (2001). Censo Nacional de Población, Hogares y Viviendas 2001. Base de datos REDATAM.

INDEC (2010). Censo Nacional de Población, Hogares y Viviendas 2010. Base de datos REDATAM y Cartografía.

Jolly, J. F. (2004). Algunos aportes para la conceptualización de la política de vivienda de interés social, VIS. Papel Político, 16, 77-102. 
Mera, G., y Marcos, M. (2012). Los censos de población como fuente de datos para trabajar a nivel microespacial (1980-2010). Pampa: Revista Interuniversitaria de Estudios Territoriales, (8), 137-162.

MINVU (2007). Medición del déficit habitacional. Guía práctica para calcular requerimientos cuantitativos y cualitativos de vivienda mediante información censal. Santiago de Chile: MINVU/División Técnica de Estudio y Fomento Habitacional (DITAC), Ministerio de Vivienda y Urbanismo.

Municipio de Morón (s/f). Cartografía de Morón por barrios. Morón: Dirección de Sistemas.

Municipio de Morón (2009). Morón diez años después. Apuntes de la gestión de Gobierno 1999-2009. Morón: Municipio de Morón

Observatorio del Conurbano Bonaerense, Universidad Nacional de General Sarmiento. http://observatorioconurbano.ungs.edu.ar/?page id=2691\#Vivienda

Pradilla, E. (1982). Ensayos sobre el problema de la vivienda en América Latina. México: Colección Ensayos Universidad Autónoma Metropolitana Xochimilco.

Rodríguez, J. (1999). Información censal relevante para la medición del déficit habitacional. En América Latina: aspectos conceptuales de los censos del 2000. Santiago de Chile: Centro Latinoamericano de Demografía (CELADE).

Sepulveda, R. y Fernández Wagner, R. (2006). Análisis crítico de las políticas nacionales de vivienda en América Latina. Costa Rica: Centro Cooperativo Sueco.

Szalachman, R. (2000). Perfil del déficit y políticas de vivienda de interés social: Situación de algunos países de la región en los noventa. Santiago de Chile: CEPAL. 